\title{
Simulation of Phytoplankton Distribution and Variation in the Bering-Chukchi Sea using a 3-D Physical-Biological Model
}

\footnotetext{
Haoguo $\mathrm{Hu}^{1}$, Jia Wang ${ }^{2}$, Hui $\mathrm{Liu}^{3}$, and Joaquim Goes ${ }^{4}$

1. Cooperative Institute for Limnology and Ecosystems Research, University of Michigan, Ann Arbor, MI. 2. NOAA. Great Lakes Environmental Research Laboratory, Ann Arbor, MI. 3. Department of Marine Biology, Texas A\&M University, Galveston, TX. 4. Lamont-Doherty Earth Observatory, Columbia University, New York, NY.
}

Key Points:

Sea ice plays a key role in algal bloom in the Bering Shelf;

Sea ice algae account for a signification of phytoplankton biomass; Plankton sinking is important for model simulations.

\begin{abstract}
A three dimensional physical-biological model has been used to simulate seasonal phytoplankton variations in the Bering and Chukchi Seas with a focus on understanding the physical and biogeochemical

mechanisms involved in the formation of the Bering Sea Green Belt (GB) and the Subsurface Chlorophyll Maxima (SCM). Model results suggest that the horizontal distribution of the GB is controlled by a combination of light, temperature, and nutrients. Model results indicated that the SCM, frequently seen below the thermocline, exists because of a rich supply of nutrients and sufficient light. The seasonal onset of phytoplankton blooms is controlled by different factors at different locations in the Bering Sea. In the off-shelf central region of the Bering Sea, phytoplankton blooms are regulated by available light. On the Bering Sea shelf, sea ice through its influence on light and temperature plays a key role in the formation of blooms, whereas in the Chukchi Sea, bloom formation is largely controlled by ambient seawater temperatures. A numerical experiment conducted as part of this study revealed that plankton-sinking is important for simulating the vertical distribution of phytoplankton and the seasonal formation of the SCM. An additional numerical experiment revealed that sea ice algae account for $14.3 \sim 36.9 \%$ of total phytoplankton production during the melting season, and it cannot be ignored when evaluating primary productivity in the Arctic Ocean.
\end{abstract}

\section{Introduction}

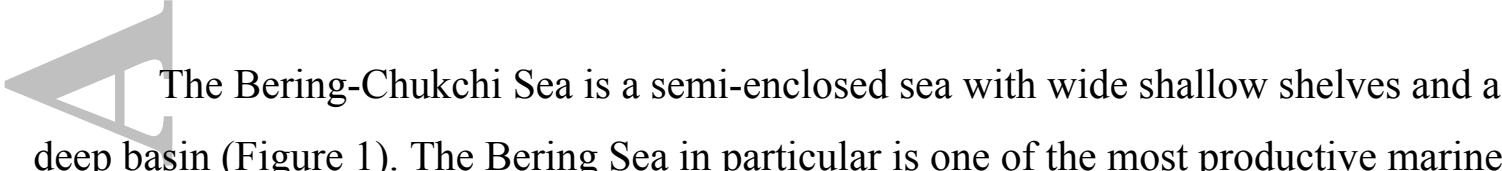
deep basin (Figure 1). The Bering Sea in particular is one of the most productive marine ecosystems in the world, accounting for more than $10 \%$ of the world's and $59 \%$ of the U.S. seafood harvest (NMFS 2014). Hence factors regulating primary productivity in this region are of particular interest.

This is the author manuscript accepted for publication and has undergone full peer review but has not been through the copyediting, typesetting, pagination and proofreading process, which may lead to differences between this version and the Version record. Please cite this article as doi:10.1002/ 2016JC011692. 
Previous research has shown the existence of regions that are particularly rich in phytoplankton biomass are the shelf-edges, which has been called "the Bering Sea Green Belt (GB) exhibiting a considerably higher rate of biological production as compared to the basin and the Bering middle shelf (Springer et al. 1996. Figure 2a). These studies have attributed the enhanced productivity of the GB to tidal mixing and transverse circulation processes. Together, these two processes contribute to nutrient enhancement in the euphotic zone, and because of their sustained nature, they aid in prolonging the spring bloom and enhancing rates of annual high production in this region. Tidal mixing in the Bering Slope and the coastal area is stronger than in the middle shelf and in the deep basin. However, there is no evidence of transverse circulation (at least in summer). If transverse circulation was present the observed summer "cold pool" in the shelf area would not form (Hu and Wang 2010).

In this study, we have used a coupled 3-D Physical-Biological Model to simulate the horizontal distributions of surface Chl-a (Figure 2b). Physical, chemical, and biological factors are inferred from the model simulations (section 3.1) and then invoked to provide an explanation for the observed surface Chl-a distribution (Figure 2a).

During summer the Bering Sea is characterized by a prominent subsurface chlorophyll maxima (SCM) (Stabeno et al. 2012; Lomas et al. 2012). During a cruise survey in 2008 (Figure 3, section $59.9^{\circ} \mathrm{N}$, see Figure 1 for location), a prominent SCM was also observed in the Bering Sea (Goes et al. 2014). Chlorophyll a concentrations in the top layer $(<20 \mathrm{~m})$ and the bottom layer $(>50 \mathrm{~m})$ were less than $0.4 \mu \mathrm{g} / \mathrm{L}$. However, right beneath the thermocline in the middle shelf, Chl-a concentrations reached levels of $15 \mu \mathrm{g} / \mathrm{L}$. To the best of our knowledge, the SCM is seldom reported in 3-D physicalbiological model simulations for the Bering Sea because of its complex environment caused by sea ice. Because the SCM contains a large part of the biomass on the Bering Shelf in summer, mechanisms leading to the formation of SCM are of interest and are discussed in section 3.2.

There have been some previous numerical studies of the Bering Sea ecosystem. These include the work by Jin et al. (2006) who used a 1-D ecosystem model to reproduce the magnitude and duration of the spring phytoplankton blooms at $12 \mathrm{~m}, 24 \mathrm{~m}$, and $44 \mathrm{~m}$ in the southeastern Bering middle shelf. Zhang et al. (2010) on the other hand, 
used a 3 $\square \mathrm{D}$ pan $\square$ Arctic biophysical model to investigate the impact of declining Arctic

69 sea ice on the marine planktonic ecosystem from 1988 to 2007. Consistent with satellite

70 measurements, the model results showed a general downward trend in summer sea ice

71 extent. In Zhang et al. (2010) it was inferred that in addition to increasing the availability

72 of photosynthetic active radiation, the decline in sea ice tends to increase the nutrient

73 availability in the euphotic zone by enhancing air $\square$ sea momentum transfer and causing

74 enhanced upwelling and mixing of nutrients in the water column.

75 In an earlier study (Wang et al. 2013), we reported preliminary model results of

76 our 3-D coupled model for the Bering-Chukchi Sea in 2007-2008. In the present study

77 we have used model outputs to describe the mechanisms and factors responsible for the

78 formation and sustenance of the "Bering Sea Green Belt", the formation of the SCM and

79 the general distribution of phytoplankton in the Bering Sea and the Chukchi Sea.

80

81

82

83

\section{The Model}

The physical model is described in detail in Wang et al. (2009, 2013), Hu and Wang (2010), and $\mathrm{Hu}$ et al. 2011. Complete details of the biological model are available in Hu et al. (2004) and Wang et al. (2013). Different from our previous studies, sea ice algae are included in this model. It is generally accepted that the community composition of sea ice algae present in the Bering and Chukchi Seas are not the same species as those found in the water columns, the former being characterized by many pennate-type diatoms instead of the centric forms often reported from the water column (McRoy and Goering 1974; Goes et al. 2014). In this study, the sea ice algae were simulated as a thin layer at the bottom of the ice. Sea ice algae are not specified to species. Furthermore, the equations and parameters used for sea ice algae are the same as used for algae in the water, except that the vertical movement and horizontal diffusivity are neglected due to the fact that sea ice algae move only with sea ice. Additionally, zooplankton predation is omitted due to little or no zooplankton grazing (McRoy and Goering 1974).

$$
\frac{\partial P}{\partial t}+u_{i} \frac{\partial P}{\partial x}+v_{i} \frac{\partial P}{\partial y}=G r o w \cdot P-m_{p} e^{\mu_{p} T} P-\left(d_{p}+\eta P\right) \cdot P
$$


96 where $\mathrm{P}$ is phytoplankton, $u_{i}$ and $v_{i}$ are sea ice velocities. Sea ice algae growth rate is

97 defined as $\operatorname{Grow} \cdot P=g_{p} e^{\mu_{p} T} \cdot \min \left(f_{n}, e^{-\gamma_{1} I}\left(1-e^{-\gamma_{2} I}\right)\right) \cdot P$

99 where the nutrient limitation function is

100

where $\mathrm{k}_{\mathrm{N}}, \mathrm{k}_{\mathrm{P}}, \mathrm{k}_{\mathrm{Si}}$ are the half-saturation constants of nitrogen, phosphate, and silicate (see surface light intensity, $k$ is the light attenuation coefficient, and $z$ is the water depth. Here, the sunrise and sunset times are calculated so the effects of day and night are included for biological growth. $m_{p} e^{-\mu_{p} T} \cdot P$ is the phytoplankton respiration function. $\left(d_{p}+\eta P\right) \cdot P$

109 is the phytoplankton mortality function, where $d_{p}$ is mortality rate, $\eta P$ is an extra term

110 for limiting phytoplankton growth.

111 Most phytoplankton cells are denser than water. The density of seawater varies

112 from about 1.021 to $1.028 \mathrm{~g} / \mathrm{cm}^{3}$, but the density of cytoplasm within phytoplankton can

113 range from 1.03 to $1.10 \mathrm{~g} / \mathrm{cm}^{3}$. Phytoplankton sinking has been discussed via Chl-a

114 measurement (Cooper et al. 2012). Evidence for phytoplankton sinking in this region is

115 available from the Russian-American Long-term Census of the Arctic (RUSALCA)

116 project observations where a large amount of Chl-a can be seen at depth (Figure 4).

117 Zooplankton may swim down to avoid light or predation in the daytime and swim 118 up at night to feed. In this study, however, we ignore the swimming and assume that they 119 sink with phytoplankton at the same speed. Unlike in our previous study (Wang et al.

120 2013), we have included the downward movement (sinking) of phytoplankton and

121 zooplankton; the equations for phytoplankton are as follow,

122

$$
\begin{gathered}
\left(\frac{d}{d t}-\nabla^{2}+W_{P} \frac{\partial}{\partial z}\right) \cdot P=G r o w \cdot P-m_{p} e^{\mu_{p} T} P-\left(d_{p}+\eta P\right) P-g_{z} e^{\mu_{p} T}\left(1-e^{\lambda P}\right) P Z \\
\left(\frac{d}{d t}-\nabla^{2}+W_{Z} \frac{\partial}{\partial z}\right) \cdot Z=\beta g_{z} e^{\mu_{z} T}\left(1-e^{\lambda P}\right) P Z-m_{z} Z-d_{z} Z \\
\left(\frac{d}{d t}-\nabla^{2}\right) \cdot N=-G r o w \cdot P+m_{p} e^{\mu_{p} T} P+m_{z} Z+\varepsilon D \\
\left(\frac{d}{d t}-\nabla^{2}+W_{D} \frac{\partial}{\partial z}\right) \cdot D=\left(d_{p}+\eta P\right) P+d_{z} Z+(1-\beta) g_{z} e^{\mu_{z} T}\left(1-e^{\lambda P}\right) P Z-\varepsilon D
\end{gathered}
$$


Where $\mathrm{N}$ represents Nitrate, Phosphate, and Silicate respectively and computed separately each with its own parameters.

126

127

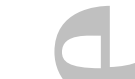

$\mathrm{W}_{\mathrm{P}}, \mathrm{W}_{\mathrm{Z}}$, and $\mathrm{W}_{\mathrm{D}}$ are the sinking velocities of phytoplankton, zooplankton, and detritus, respectively; u, v, w are water velocities; $K_{h}$ and $K_{v}$ are the horizontal and vertical turbulent diffusivity coefficients, $g_{z} \cdot P \cdot e^{\mu_{p} T}\left(1-e^{\lambda P}\right) \cdot Z$ is the zooplankton grazing function, $\varepsilon$ is the detritus remineralization rate. Previous research has shown that the grazing rates are different among inner, middle, and outer shelf (Stoecker et al. 2014), however, it is not our concern and for simplification then we have ignored these differences in the model, and use an identical $\mathrm{g}_{\mathrm{z}}$. Parameter values and units are listed in Table 1.

\subsection{Model configuration and forcing} northern boundary and $\sim 9 \mathrm{~km}$ near the Aleutian Islands and dy $=\sim 9 \mathrm{~km}$, covering the whole Bering and Chukchi Seas. There are 24 sigma levels for the ocean model in the vertical (at $\sigma=0,-0.008,-0.016,-0.031,-0.063,-0.125,-0.188,-0.250,-0.313,-0.375$, $0.438,-0.500,-0.563,-0.625,-0.688,-0.750,-0.813,-0.875,-0.938,-0.969,-0.984,-$

$1440.992,-0.996,-1$; where $\sigma=\frac{z-\eta}{H+\eta}$, $\mathrm{z}$ is vertical coordinate and negative downward, $\eta$

145 is the mean water elevation, and $\mathrm{H}$ is the water depth). The vertical resolution is higher 146 near the surface and the bottom for a better representation of the surface and bottom 147 boundary layers.

148 The model was initialized with climatologic temperature and salinity data from 149 the Polar Science Center Hydrographic Climatology (PHC 3.0, Steele et al. 2001). 150 National Centers for Environmental Prediction (NCEP) 6-hourly reanalysis data 
consisting of wind, air temperature, shortwave radiation, precipitation, humidity, and sea level pressure were used to drive the model. The sea ice velocity, concentration, and thickness were set to zero as initial conditions. The model was run for years 2007-2012 with 6-hourly atmospheric forcing.

The initial conditions for nutrients were derived from the World Ocean Database 2009 , which archives the digitized annually mean nitrate $\left(\mathrm{NO}_{3}\right)$, phosphate $\left(\mathrm{PO}_{4}\right)$, and silicate $\left(\mathrm{SiO}_{3}\right)$ in a grid format of $2 \times 2$ degrees at standard depths. Seasonal surface Chl-a concentrations were used, and there were no usable zooplankton data. These annually averaged data were interpolated into the model grids in both horizontal and vertical directions. Along the lateral open boundaries, the same annual mean data were used to prescribe the boundary forcing to the model with no interannual variability.

Satellite measurements of Chl-a concentration (Figure 2a) from the Sea-viewing Wide Field-of-view Sensor (SeaWiFS) were obtained from the NASA Ocean Biology Processing Group's data archive (http://oceandata.sci.gsfc.nasa.gov/). The standard local area coverage $(1 \mathrm{~km}) \mathrm{Chl}$-a product was utilized.

In situ measurements are from two International Polar Year cruises in the Bering and Chukchi Seas. The Bering Sea cruise on the southeastern Bering shelf that occurred July 4-23, 2008 (depicted as transect BS, Figure 1) was part of a Bering Sea Ecosystem Study (BEST). The Chukchi Sea cruise occurred on RUSALCA on the southern Chukchi Sea during Sept. 6-29, 2009 (transect AL in Figure 1).

\section{Results}

The physical model results have been described in Wang et al. (2009, 2013), Hu and Wang (2010), and $\mathrm{Hu}$ et al. (2011). In this study, our focus is only the biological parts.

\subsection{The horizontal phytoplankton distributions}

The observed horizontal distributions of phytoplankton biomass in the Bering Sea (Figure 2a) show an obvious high production along the continental shelf (GB). Here the mechanisms of the GB formation were numerically examined: how the nutrients, light, and temperature control phytoplankton growth. 
From May to Sept. (Figure 5a), the surface nutrients $f_{n}=\min \left(\frac{N}{N+k_{N}}, \frac{P}{P+k_{P}}\right.$,

$\frac{S i}{S i+k_{S i}}$ ) were consumed to a low level in the southern Bering Sea, whereas in the

184 northern Bering Sea, nutrients remain relatively high owing to the gradual melting of ice

185 cover. Also, worthy of note is the relatively high nutrients around the coast, the Aleutian

186 Islands, and the Bering Slope areas. It is worth mentioning that vertical mixing plays a

187 significant role in the distribution of nutrients. Though the vertical mixing is relatively

188 weak due to stratification in summer time (May-Sep), while in the coastal areas and

189 Bering Slope, it is relatively strong because of the coastal current plus tidal mixing and

190 the strong slope current, respectively.

191 The light factor $f_{L}=e^{-\gamma_{1} I}\left(1-e^{-\gamma_{2} I}\right)$ unsurprisingly gradually abates from the

192 south to the north (Figure 5b). In addition in the western Chukchi Sea is lower than the

193 east because of sea ice cover.

194 The minimum of light and nutrients $f_{n L}=\min \left(f_{n}, f_{L}\right)$ is shown in Figure 5c. The

195 light factor reduces the south-north difference caused by nutrients, and the integrated

196 factor enhances the Bering Slope and Aleutian Islands areas, where both nutrients and

197 light are relatively high.

198 The temperature factor $f_{T}=m_{p} e^{-\mu_{p} T}$ is shown in Figure $5 \mathrm{~d}$, which indicates the

199 expected gradual reduction with latitude to north. In the case of the coastal area,

200 especially in the Bering inner shelf, the temperature is relatively high due to the shallow

201 water, and also high in the Bering Slope area, where the Slope Current carries warm

202 water to the north along the slope.

203 The total integrated growth factor grow $=f_{T} \cdot f_{n L}$ is shown in Figure 5e. It

204 appears that the coastal area, Aleutian Islands, and the Slope area are characterized with

205 higher values compared to the adjacent areas.

206 The increased quantity per hour is described with $\Delta \mathrm{P}=f_{T} \cdot f_{n L} \cdot \mathrm{P}$ (Figure $5 \mathrm{f}$ ).

207 Surprisingly, the quantity in the northern Bering Sea and the Chukchi Sea is low when

208 compared to its growing factor in Figure 5e. This is because the phytoplankton quantity

209 (P) remains relatively low year-round in these areas. 
Overall, if we compare increased quantity in Figure $5 \mathrm{f}$ with the observed and simulated horizontal distributions in Figure 2, it is clear that the distributions are not determined by any single bio-geochemical/physical factor, but by the integrated effects.

\subsection{The Subsurface Chlorophyll Maxima}

During the 2008 cruise, a subsurface phytoplankton bloom was observed right beneath the thermocline from $30 \mathrm{~m}$ to $50 \mathrm{~m}$ in the middle Bering shelf (Figure 3a), but mechanisms leading to the formation of the SCM beneath the thermocline and the factors regulating its formation and maintenance have not been examined in previous coupled physical-biological modeling studies. Similar to the previous section, the controlling factors (nutrients, light, and temperature) unveil the mechanism behind the observations.

A location was selected in the middle shelf $\left(175^{\circ} \mathrm{W}, 60^{\circ} \mathrm{N}\right)$, where water depth was 105 $\mathrm{m}$, and the summer thermocline was within 20-40 $\mathrm{m}$.

Nutrients play a notable role in phytoplankton growth (Figure 6a). In winter (from Dec to Mar), nutrients are rich and are not a limiting factor. In the bottom layer, nutrients remain rich year round. In comparison, the summer nutrients in the top layer (0-30 m) were at a very low level, which is very unfavorable to phytoplankton growth.

Light attenuates from top to bottom in the water column (Figure 6b). In winter, weak light penetrates to a very shallow layer or reduces to none when thick sea ice is present. In summer, strong light reaches the deep layer. In other seasons, appropriate intensity light is favorable to phytoplankton growth.

When examining the minimum factors of light and nutrients, the top layer $(0-30 \mathrm{~m})$ is limited by nutrients, and the bottom layer is limited by light. As a result, $\mathrm{f}_{\mathrm{nL}}$ maxima appear in subsurface in summer (Figure 6c).

The temperature factor is shown in Figure 6d. Temperature has an exponential relation to growth function; this means that growth rates are higher at higher temperatures and vice versa. It is worth mentioning that in the real ocean, however, individual species have their own preferred thermal conditions; some prefer high temperature, and some prefer low temperature. In this study, species are not specified, thus the species-specific preferences are ignored; we only describe a general trend. 
Temperature factor $f_{T}$ multiplies $f_{n L}$ is shown in Figure 6e. This is the actual growth factor to the phytoplankton.

The vertical turbulent mixing coefficient is shown in Figure $6 \mathrm{f}$. The coefficient is high in fall and winter and low in spring and summer. It is high in the top and bottom layers because of wave and tidal mixing, respectively. Weak mixing favors phytoplankton accumulation, while strong mixing acts in an opposite way. Thus, the spring bloom could be stronger than the fall bloom due to dynamic mixing, even though the other factors remain constant.

During the summer, vertical mixing is very weak in the middle shelf. It is difficult for rich bottom nutrients to penetrate the thermocline. At the same time, intensive light can reach the under-thermocline layer. If temperature is suitable, a SCM can develop (Figure 6g).

For completion and to show the model performance, the modeled Chl-a is shown in Figure $3 \mathrm{~b}$ and the observed and modeled nutrients are shown in Figure 3c-3h. Modeled and shipboard derived fields of Chl-a and nutrients shown in these figures show remarkable consistency, giving us immense confidence in the performance of our model.

\section{Discussion}

\subsection{The spatial characteristics of bloom timing}

Light controls the phytoplankton bloom in the deep Bering Sea basin. In the Bering basin (Figure 7c), the phytoplankton bloom starts at the end of February, reaches a peak in March, and maintains a high value of $4 \mathrm{mg} / \mathrm{m}^{3}$ until April. In February, the temperature is low, however, the nutrients are rich. Once the light intensity is sufficient, phytoplankton starts to bloom and continue into May. Meanwhile, nutrients drop sharply from $10 \mu \mathrm{mol} / \mathrm{L}$ to $4 \mu \mathrm{mol} / \mathrm{L}$ due to phytoplankton consumption.

On the other hand, sea ice appears to play a key role in phytoplankton blooms over the Bering shelf. On the shelf (Figure 7b), sunlight is adequate in April and May, the temperature remains as low as $\sim-1.87^{\circ} \mathrm{C}$, and nutrients are rich throughout the spring. However, phytoplankton are not able to grow due to the low temperature and low light availability in the water caused by sea-ice cover. When sea ice begins melting, 
phytoplankton start growing to form blooms. The south to north differences in the timing of the onset of the bloom on the Bering Sea shelf is a reflection of the influence of sea-ice on phytoplankton photosynthesis and growth. Figure $7 \mathrm{~d}$ shows the interannual variations of phytoplankton blooms on the Bering Sea shelf. The blooms of 2008 appeared in May, those of 2009 in April, and the blooms of 2010 in May. It is clear that in all three years, these interannual differences in the timing of the blooms were tightly connected to sea ice melting. Observations verified that spring bloom timing is related to ice retreat timing, if ice was presented on the Bering Shelf after mid-March (Sigler et al. 2014).

Temperature plays an important role in the Chukchi Sea phytoplankton bloom (Figure 7a). The nutrient factor remains at a locally high level from November until the following July; the light factor picks up in May; and sea ice cover retreats in June. However, the bloom does not appear to be connected with sea ice melt, as observed on the Bering shelf. Rather, the bloom starts in early August because light in the Chukchi Sea is as low as $4 \mathrm{~W} / \mathrm{m}^{2}$, which is lower than the $6 \mathrm{~W} / \mathrm{m}^{2}$ in the Bering Shelf, and it has to wait for the temperature to pick up to promote rapid growth.

In summary, although the growth requirements (i.e. nutrients, light, and temperature) for phytoplankton of the entire Bering Sea shelf and the Chukchi Sea are not dissimilar, the manner in which they interact with each other in different regions has a large influence on the onset and timing of the blooms. Nutrients are never the triggering factor for the spring-summer bloom, but light and temperature are, and it would appear to make sense to ascribe sea ice melt as the most important driver of the variances in the timing of the blooms.

In the case of the fall bloom, its timing is far less related to temperature and light conditions. Nutrients appear to play a far greater role at this time of the year. The surface water temperature drops because of surface cooling, making the water column vertically unstable, which helps bring bottom nutrient-rich water to the top layer, and in turn supports a fall bloom. The fall bloom only occurs in the Bering Shelf. In the case of the deep basin, the rate at which these nutrients arrive in the upper layer is very slow and is therefore unfavorable to bloom formation. On the other hand, in the Chukchi Sea, 
nutrients rise fast, but the light drops even faster, and at the same time, sea ice forms to a rigid lid and prevents light penetration.

\subsection{Experiments with/without plankton sinking}

Two comparable model tests were conducted: one with the inclusion of plankton sinking and the other without. Model outputs for an entire year with and without plankton sinking are shown in Figures 8a-b. In the non-sinking case, the vertical distribution of phytoplankton shows high values in spring, persisting at the surface until the start of June, and declining to form an SCM thereafter at around 20-30 m, which disappears by late Aug/early Sept. (Figure 8a). With sinking, the bloom at the surface starts declining by the end of May, to form an SCM around 30-40m by the end of June, persisting until the end of Sept. (Figure $8 \mathrm{~b}$ ) The seasonal evolution of the surface phytoplankton bloom and the formation of the SCM seen in Fig. $8 \mathrm{~b}$ is more consistent with in-situ observations (Cooper 2012).

\subsection{With/without sea ice algae}

It has been equivocal whether sea ice edge algal blooms are seeded by ice algae released from melting ice (Schandelmeier and Alexander, 1981. Garrison et al., 1987) or not (McRoy and Goering 1974; Goes et al. 2014). Chl $a$ concentration within sea ice can reach $120 \mathrm{mg} / \mathrm{m}^{3}$ in the Arctic Ocean (Meguro et al. 1966), and ranged from 1.20 to 48.0 $\mathrm{mg} / \mathrm{m}^{3}$ in Amundsen Sea, Antarctica (computed from Arrigo et al. 2014, where 1.80 to $72.2 \mathrm{mg} / \mathrm{m}^{2}$ in depth-integrated with an averaged sea ice thickness $1.5 \mathrm{~m}$ ), these are as high or higher an order of magnitude as of blooms in open water. To verify the sea ice algal impact on the bloom, two comparable cases were conducted to examine the model behavior with/without sea ice algae.

With sea ice algae (Figure 9a, 9b), the growth equations are similar to the algae in the water except they move with ice and do not have vertical movement. Their growth depends on light, temperature, and nutrients. At the bottom of ice, temperature stays stable at $\sim-1.83{ }^{\circ} \mathrm{C}$ (depends on salinity). The nutrients are rich enough to support the growth (Figure 9b). The controlling factor is light, which is sensitive to ice thickness. Ice algae start to grow at the beginning of February and, with increasing sunlight, they grow 
fast from April to May (the melting season) and are eventually released into water when sea ice melts in May and June. Due to excess consumption by ice algae, the surface nutrients tended to stay lower (the lowest is $30 \%$ ) when compared to the no-ice-algae case. With the release of ice algae, the phytoplankton biomass in the surface water increased faster, by almost $35 \%$, as compared to the no sea ice algae case. Also worthy of mention is that after the bloom peak, the surface phytoplankton decreased faster than the no-ice-algae case because of the reduced availability of nutrients in the water column.

An examination of the integrated phytoplankton biomass on the Bering Shelf from June 1 to July 15 (Figure 9c), revealed an average 14.3\% difference between the two cases; within the Chukchi Shelf, the average difference from July 15 to September 15 rose to $36.9 \%$. This suggests that sea ice algae was largely responsible for the increase in total phytoplankton biomass in the water column during the ice melting season. Ignoring the contribution of sea ice algae, it lowered the total annual phytoplankton biomass by $3 \%$ in the Bering Shelf, and at least a $12 \%$ in the Chukchi Sea.

\section{Conclusions}

The observed Bering Sea Green Belt was thoroughly studied using a coupled 3D physical-biological model. Model results indicate that the distributions are not driven by a single physical or biogeochemical factor, but instead, by a combination of factors.

Observations show that the SCM of the Bering Sea shelf exists in the layer directly below the thermocline. Model results suggest that during the summer, vertical mixing is very weak on the middle shelf, and rich bottom nutrients (beneath the thermocline) do not penetrate the thermocline. In addition, strong light can penetrate the thermocline. These factors create conditions suitable for the development of the SCM. The spatial bloom timing depends on various factors. While light availability controls the phytoplankton bloom in the deep Bering basin, sea ice plays a key role in phytoplankton bloom in the Bering Sea shelf through its influence on seawater temperature and light. In the Chukchi Sea, temperature appears to play a far more important role in the formation of phytoplankton blooms. 
Model experimental results suggested that that vertical distribution of Chl-a and the evolution of the SCM are more realistic if plankton-sinking is included in the model simulations. Our results suggest that sea ice algae account for a signification of phytoplankton biomass during sea ice melting season, and it cannot be ignored in modeling phytoplankton in the Arctic Ocean.

Acknowledgments. We appreciate support from NOAA RUSALCA (Russian-American Long-term Censes of the Arctic) International Polar Year modeling project and NASA interdisciplinary Science Award NNX11AP28G. We thank Cathy Darnell and Nicole Rice for editing drafts. This is GLERL Contribution No. 1814. For the data used in this paper, please contact hghu@umich.edu

\section{References}

Arrigo, K. R., Brown, Z. W, \& Mills, M. M. (2014). Sea ice algal biomass and physiology in the Amundsen Sea, Antarctica. Elementa. Retrieved 24 November 2014. doi:10.12952/journal.elementa.000028

Cooper, L. W., M. Janout, K. E. Frey, R. Pirtle-Levy, M. Guarinello, J. M. Grebmeier \& J. R. Lovvorn (2012), The relationship between sea ice break-up, water mass variation, chlorophyll biomass, and sedimentation in the northern Bering Sea. Deep Sea Research II 65-70, 141-162.

Eppley, R.W. (1972), Temperature and phytoplankton growth in the sea. Fish Bull, 70:1063-1085.

Garrison, D. L., K. R. Buck, and G. A. Fryxell (1987), Algal assemblages in Antarctic pack ice and ice-edge plankton, J. Phycol., 23, $564-572$.

Goes, J., M. Gomes, E. Haugen, K. McKee, E. D'Sa, A. Chekalyuk, D. Stoecker, P. Stabeno, S. Saitoh, R. Sambrotto, 2014, Fluorescence, pigment and microscopic characterization of Bering Sea phytoplankton community structure and photosynthetic competency in the presence of a Cold Pool during summer, Columbia University Academic Commons, Deep Sea Research II, Volume 109, 2014, doi.org/10.7916/D8GM85CM.

Hu, H., Z. Wan, and Y. Yuan (2004) Simulation of seasonal variation of phytoplankton in the South Yellow Sea and analysis on its influential factors. Acta Oceanologica Sinica (In Chinese with an English abstract), 6, 74-88.

Hu, H. and J. Wang (2010), Modeling effects of tidal and wave mixing on circulation and thermohaline structures in the Bering Sea: Process studies, J. Geophys. Res., 115, C01006, doi:10.1029/2008JC005175.

Hu, H. and J. Wang, and D.R. Wang (2011), A model-data study of the 1999 St. Lawrence polynya in the Bering Sea. J. Geophys. Res., 116, C12018, doi:10.1029/2011JC007309.

Lomas, M. W., S. B. Moran, J. R. Casey, D. W. Bell, M. Tiahlo, J. Whitefield, R. P. Kelly, J. T. Mathis, and E. D. Cokelet. "Spatial and seasonal variability of primary production on the Eastern Bering Sea shelf." Deep Sea Research Part II: Topical Studies in Oceanography 65 (2012): 126-140.

Ivlev, V.S. (1945), The biological productivity of waters. Usp Sovrem Biol, 19:98-120.

Jin, M., C.J. Deal, J. Wang, N. Tanaka, and M. Ikeda (2006), Vertical mixing effects on the phytoplankton bloom in the southeastern Bering Sea mid-shelf. J. Geophys. Res., 111, C03002, doi:10.1029/2005JC002994. 
McRoy, C.P., and J.J. Goering (1974) The influence of ice on the primary productivity of the Bering Sea. Oceanography of the Bering Sea with Emphasis on Renewable Resource (D.W. Hood and E. J. Kelley), pp. 403-421. Institute of Marine Science, University of Alaska, Fairbanks, Alaska.

Meguro, H, K., Ito, and H., Fukushima (1966). Diatoms and the ecological conditions of their growth in sea ice in the Arctic Ocean. Science, Vol 152, No. 3725.

NMFS 2014,

http://www.st.nmfs.noaa.gov/Assets/commercial/fus/fus14/documents/FUS\%202014\%20FINAL.pdf.

Platt, T, Gallegos, C.L. and Harrison, W.G. (1980), Photoinhibition of photosynthesis in natural assemblages of marine phytoplankton. J. Mar Res. 38:687-701.

Schandelmeier, L., and V. Alexander (1981), An analysis of the influence of ice on spring phytoplankton population structure in the southeast Bering Sea, Limnol. Oceanogr., 26, 935 943.

Sigler M., P. Stabeno, L. Eisner, J. Napp, and F. Mueter. Spring and fall phytoplankton blooms in a productive subarctic ecosystem, the eastern Bering Sea, during 1995-2011. Deep Sea Research II, 2014, V109, P71-83, doi:10.1016/j.dsr2.2013.12.007

Springer, A.M., C.P. McRoy, and M.V. Flint (1996), The Bering Sea Green Belt: shelf-edge processes and ecosystem productivity. Fisheries Oceanography, 35, 205-223.

Stabeno, P.J., E. Farley, N. Kachel, S. Moore, C. Mordy, J.M. Napp, J.E. Overland, A.I. Pinchuk, and M.F. Sigler (2012): A comparison of the physics of the northern and southern shelves of the eastern Bering Sea and some implications for the ecosystem. Deep-Sea Res. II, 65-70, 14-30, doi: 10.1016/j.dsr2.2012.02.019.

Steele, M., R. Rebecca, and W. Ermold (2001), PHC: A global ocean hydrography with a high-quality Arctic Ocean. J. Climate, 14, 2079-2087.

Stoecker, D., A. Weigel, and J. Goes. Microzooplankton grazing in the Eastern Bering Sea in summer, Deep Sea Research II, 2014, V109, P145-156, doi:10.1016/j.dsr2.2013.09.017

Wang, J., H. Hu, K. Mizobata, and S. Saitoh (2009), Seasonal variations of sea ice and ocean circulation in the Bering Sea: A model-data fusion study. J. Geophys. Res. 114, C02011, doi:10.1029/2008JC004727.

Wang, J., H. Hu, J. Goes, J. Miksis-Olds, C. Mouw, E. D'Sa, H. Gomes, D.R. Wang, K. Mizobata, S. Saitoh, and L. Luo. A modeling study of seasonal variations of sea ice and plankton in the Bering and Chukchi Seas during 2007-2008. Journal of Geophysical Research, Oceans 118:1-14

(DOI:10.1029/2012JC008322) (2013).

Zhang, J., Y. H. Spitz, M. Steele, C. Ashjian, R. Campbell, L. Berline, and P. Matrai (2010), Modeling the impact of declining sea ice on the Arctic marine planktonic ecosystem, J. Geophys. Res., 115, C10015, doi:10.1029/2009JC005387. 
464 Table 1. Parameters used in this study

\begin{tabular}{|c|c|c|c|c|}
\hline \multicolumn{2}{|r|}{ Description } & \multirow{2}{*}{$\begin{array}{c}\text { Value } \\
0.080\end{array}$} & \multirow{2}{*}{$\begin{array}{r}\text { Unit } \\
\mathrm{h}^{-1}\end{array}$} & \multirow{2}{*}{$\begin{array}{l}\text { Reference } \\
\text { This study }\end{array}$} \\
\hline$g_{P}$ & Maximum phytoplankton growth rate & & & \\
\hline$\mu_{\mathrm{p}}$ & Exponent coefficient related to temperature & 0.0633 & ${ }^{\circ} \mathrm{C}^{-1}$ & Eppley, 1972 \\
\hline$m_{\mathrm{p}}$ & Maximum phytoplankton respiration rate & 0.001 & $\mathrm{~h}^{-1}$ & This study \\
\hline$d_{\mathrm{p}}$ & Phytoplankton mortality rate & 0.003 & $h^{-1}$ & This study \\
\hline$\gamma_{1}$ & Light inhibition coefficient & 0.0536 & $\mathrm{~m}^{2} / \mathrm{W}$ & Platt, 1980 \\
\hline$\gamma_{2}$ & Light acclimation coefficient & $1.795 \mathrm{E}-3$ & $3 \mathrm{~m}^{2} / \mathrm{W}$ & Platt, 1980 \\
\hline & Phytoplankton attenuation rate & 1.5 & $\mathrm{~m}^{3} / \mathrm{mg}$ & Ivlev,1945 \\
\hline$g_{\mathrm{z}}$ & Maximum zooplankton growth rate & 0.025 & $\mathrm{~h}^{-1}$ & Ivlev, 1945 \\
\hline & Exponent coefficient related to temperature & 0.06 & ${ }^{\circ} \mathrm{C}^{-1}$ & Ivlev, 1945 \\
\hline$m_{\mathrm{z}}$ & Maximum zooplankton excretion & 0.005 & $\mathrm{~h}^{-1}$ & This study \\
\hline$d_{\mathrm{z}}$ & Zooplankton mortality rate & 0.005 & $\mathrm{~h}^{-1}$ & This study \\
\hline$\beta$ & Zooplankton assimilation efficiency & 0.80 & & This study \\
\hline$k_{\mathrm{Si}_{\mathrm{i}}}$ & Half-saturation constant for silicate & 4.0 & $\mathrm{mmol} / \mathrm{m}^{3}$ & This study \\
\hline$k_{\mathrm{n}}$ & Half-saturation constant for nitrogen & 3.0 & $\mathrm{mmol} / \mathrm{m}^{3}$ & This study \\
\hline$k_{\mathrm{p}}$ & Half-saturation constant for phosphate & 0.2 & $\mathrm{mmol} / \mathrm{m}^{3}$ & This study \\
\hline & Detritus re-mineralization rate & 0.010 & $\mathrm{~h}^{-1}$ & This study \\
\hline$W_{\mathrm{P}}$ & Phytoplankton sinking velocity & 1.0 & $\mathrm{~m} /$ day & This study \\
\hline$W_{\mathrm{Z}}$ & Zooplankton sinking velocity & 1.0 & $\mathrm{~m} /$ day & This study \\
\hline$W_{\mathrm{D}}$ & Detritus sinking velocity & 3.0 & $\mathrm{~m} /$ day & This study \\
\hline & Phytoplankton self-limiting factor & 5.E-4 & & This Study \\
\hline
\end{tabular}

465

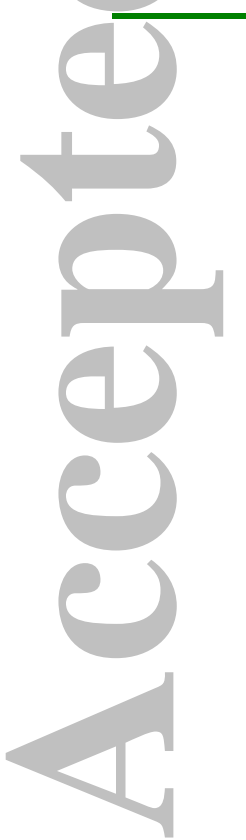




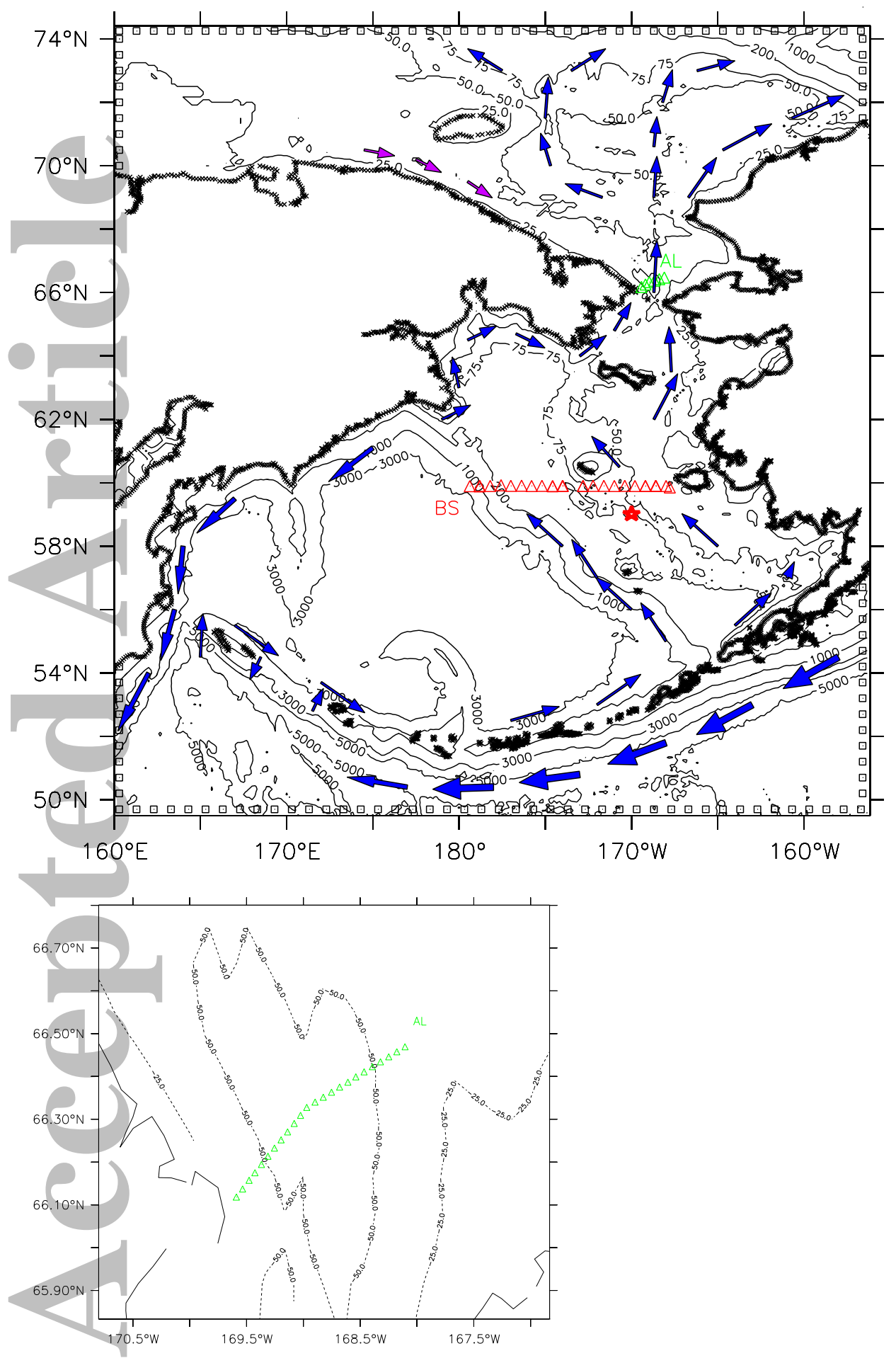

Figure 1. (a) Model domain and open boundaries, contour lines denote water depths. Cruise transect AL is shown in green and transect BS in red triangles. The red star denotes the Subsurface Chlorophyll Maxima site (see section 3.2 and section 4.1). Currents are shown in blue arrows, and the seasonal North Siberian Current is shown in purple arrows. (b) Expanded section AL. 

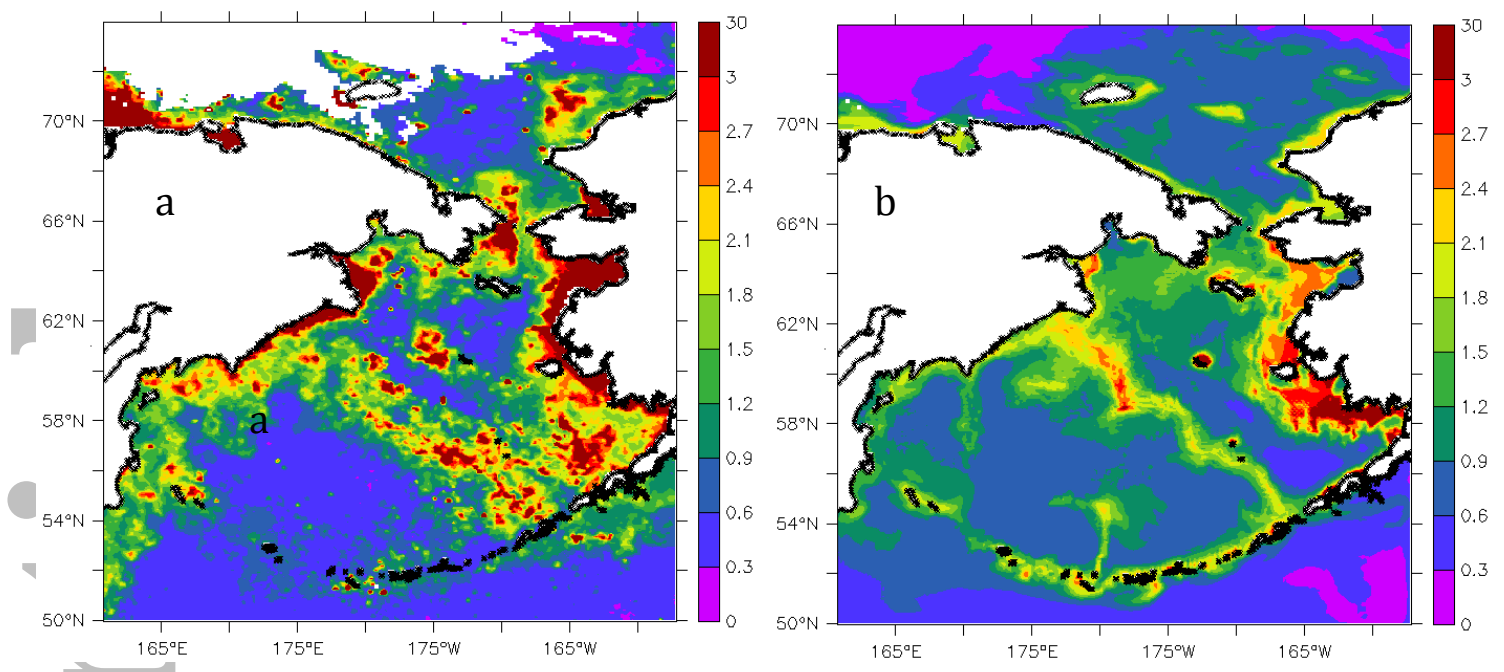

Figure 2. (a) Observed average surface Chl-a (May-Sept. 2009, SeaWiFS. The remainder of year is not included because of sea ice cover and a lack of SeaWiFS data). (b) Simulated average surface Chl-a (MaySept. 2009).

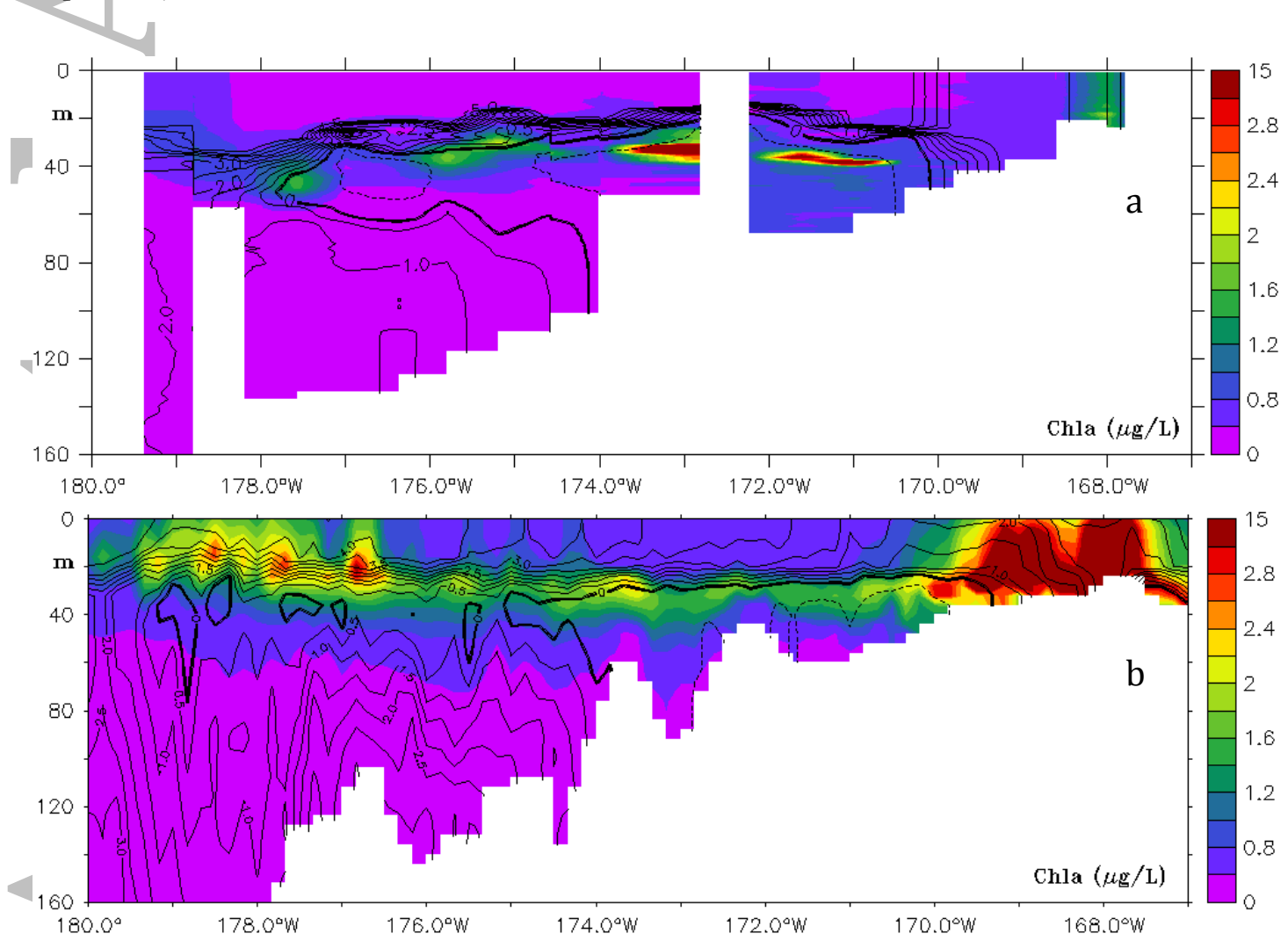



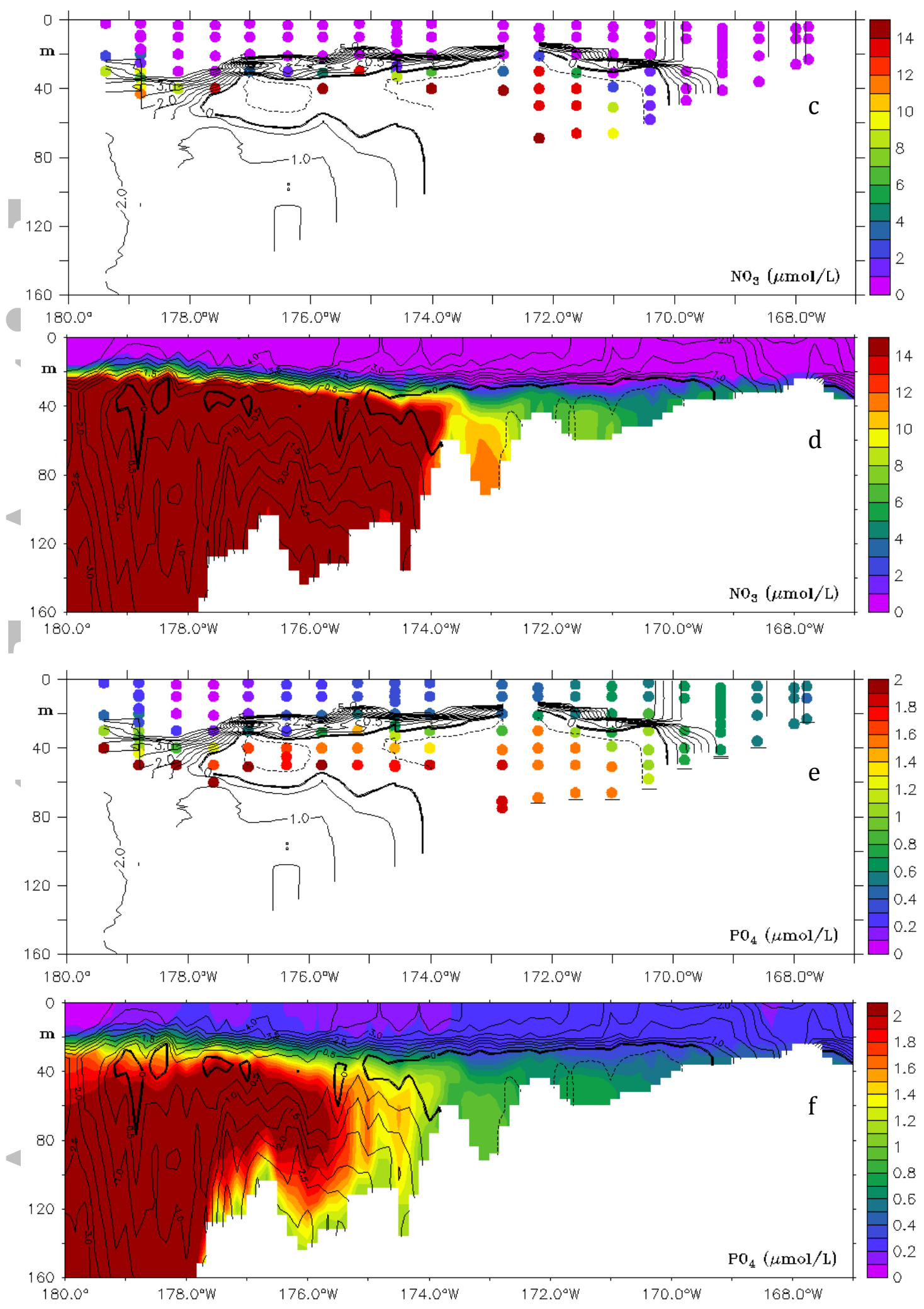


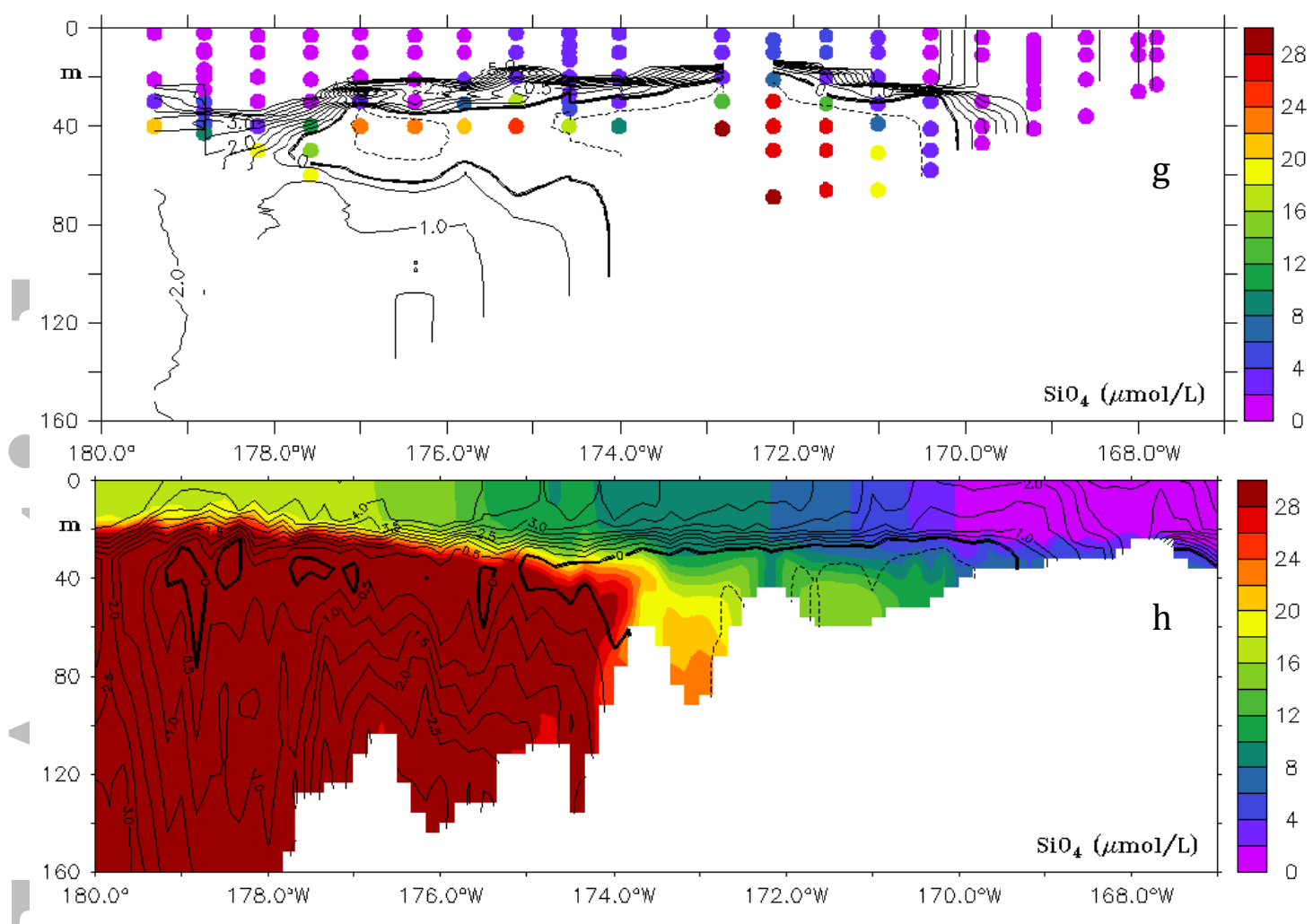

Figure 3. Chl-a (color filled), nutrients (color filled), and temperature $\left({ }^{\circ} \mathrm{C}\right.$, contour lines) along transect BS. See Figure 1 for location of transect. Figs 3 (a, c, e, g) are based on field measurements from July 2008 cruise; whereas Figs. 3 (b, d, f, h) are model results.

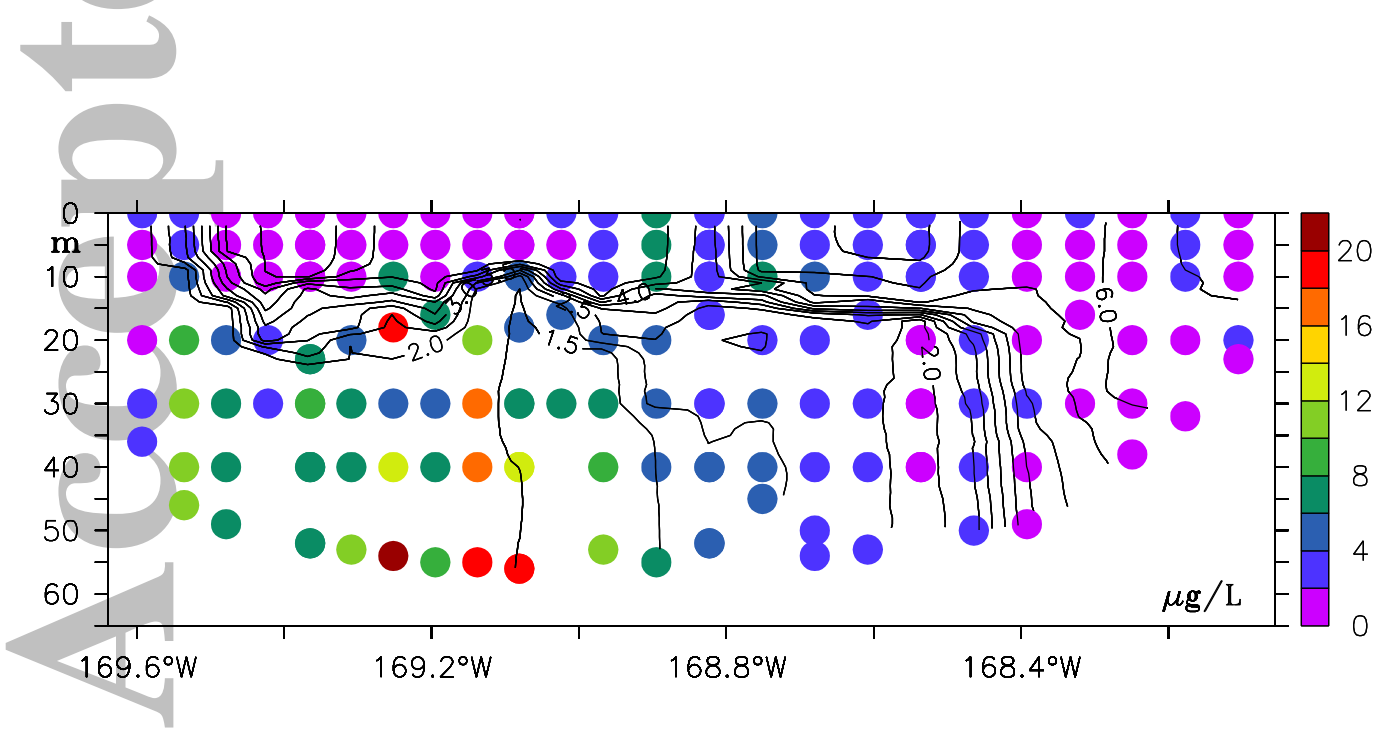

Figure 4. Chl-a in colored circles and temperature in contour lines of section AL (see Figure 1 for location), Sep. 2009, RUSALCA cruise. 


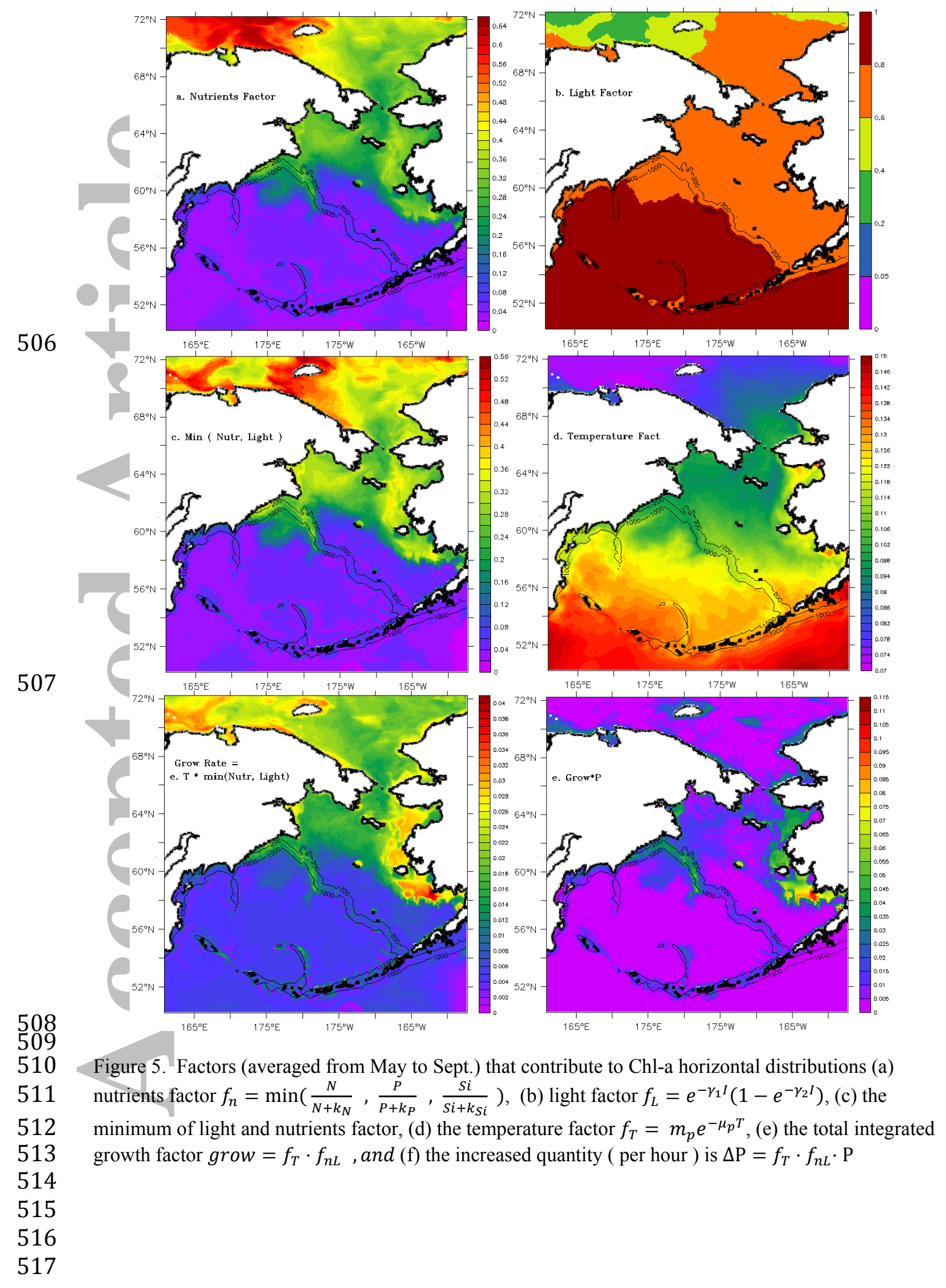




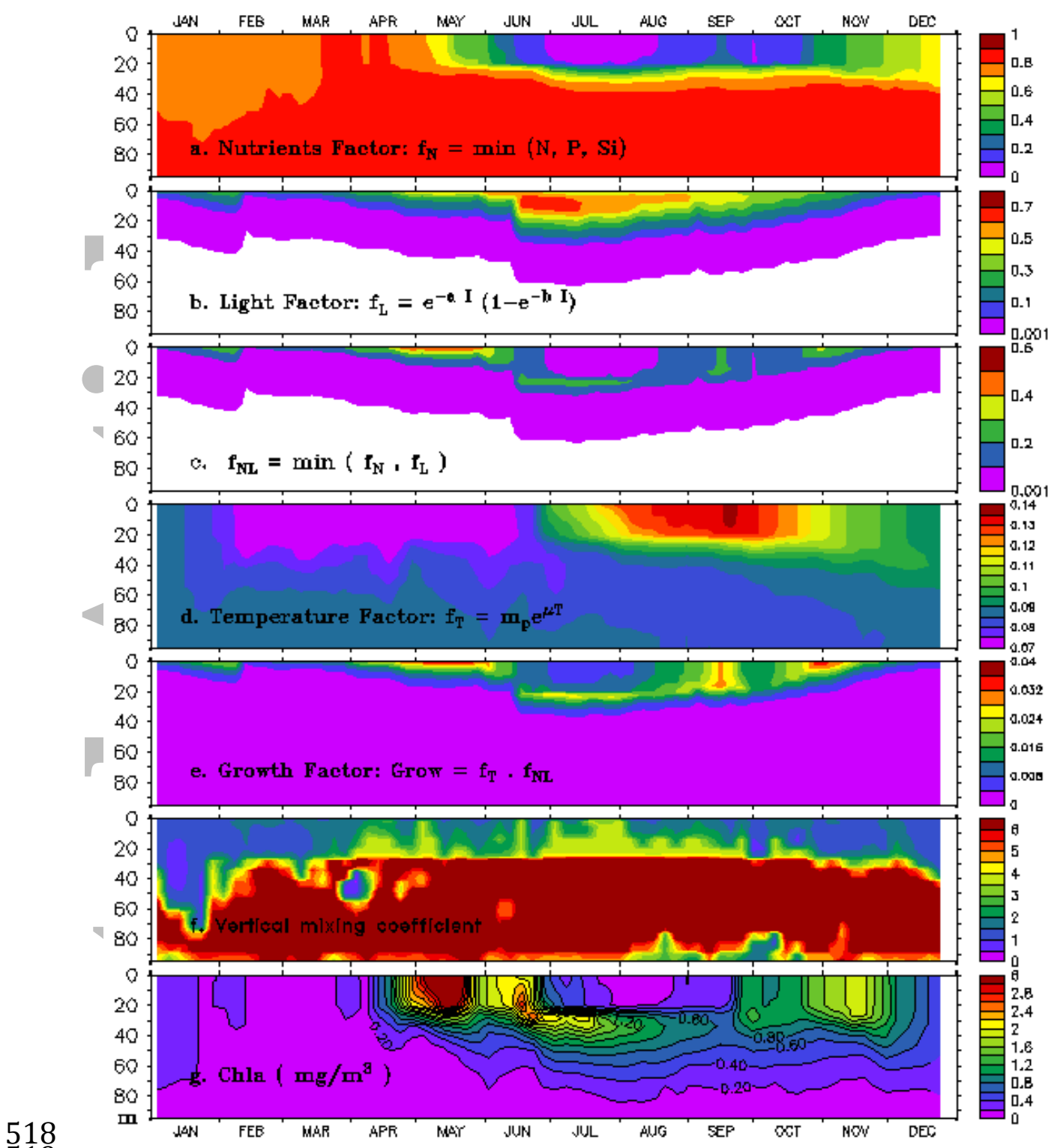

520 Figure 6. Factors that control summer SCM. (a) nutrient factor $f_{n}=\min \left(\frac{N}{N+k_{N}}, \frac{P}{P+k_{P}}, \frac{S i}{S i+k_{S i}}\right)$, (b)

521 light factor $f_{L}=e^{-\gamma_{1} I}\left(1-e^{-\gamma_{2} I}\right)$, (c) the minimum of light and nutrients factor, (d) the temperature factor $522 f_{T}=m_{p} e^{-\mu_{p} T}$, (e) the total integrated grow factor $g r o w=f_{T} \cdot f_{n L}$, (f) the vertical mixing coefficient $523-\log \left(K_{v}\right)$, and $(\mathrm{g})$ modeled Chl-a variation in 2010. 

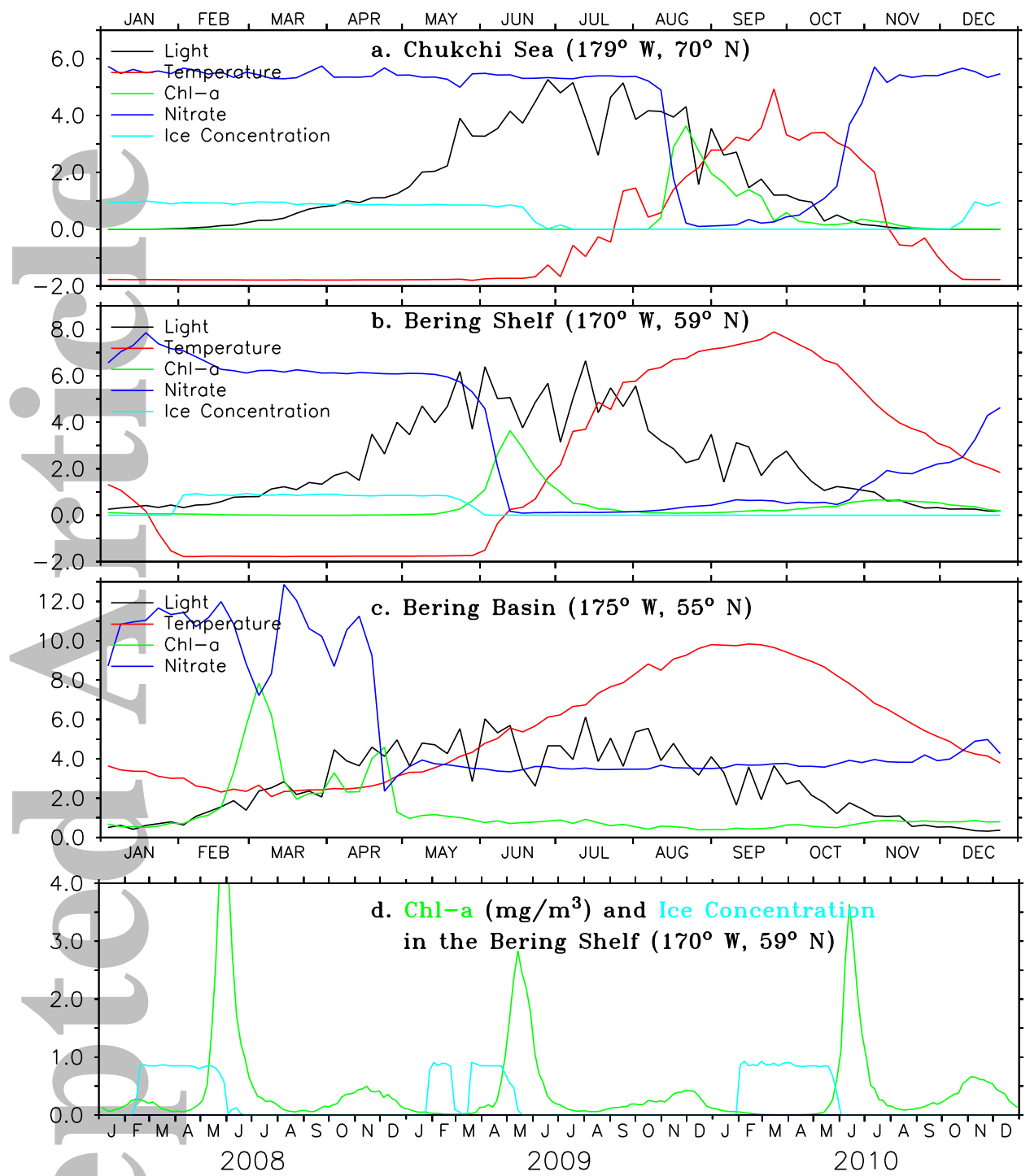

Figure 7. Spatial difference of bloom timing in 2010, light in black, temperature in red, Chl-a in green, nitrate in blue, and sea ice concentration in light blue. (a) In Chukchi Sea $\left(191^{\circ} \mathrm{W}, 70^{\circ} \mathrm{N}\right)$, (b) in Bering Shelf $\left(170^{\circ} \mathrm{W}, 59^{\circ} \mathrm{N}\right)$, (c) in Bering Basin $\left(175^{\circ} \mathrm{W}, 55^{\circ} \mathrm{N}\right)$, and (d) Chl-a and sea ice concentration in Bering Shelf $\left(170^{\circ} \mathrm{W}, 59^{\circ} \mathrm{N}\right.$, see Figure 1 star for location) of multiple years. 


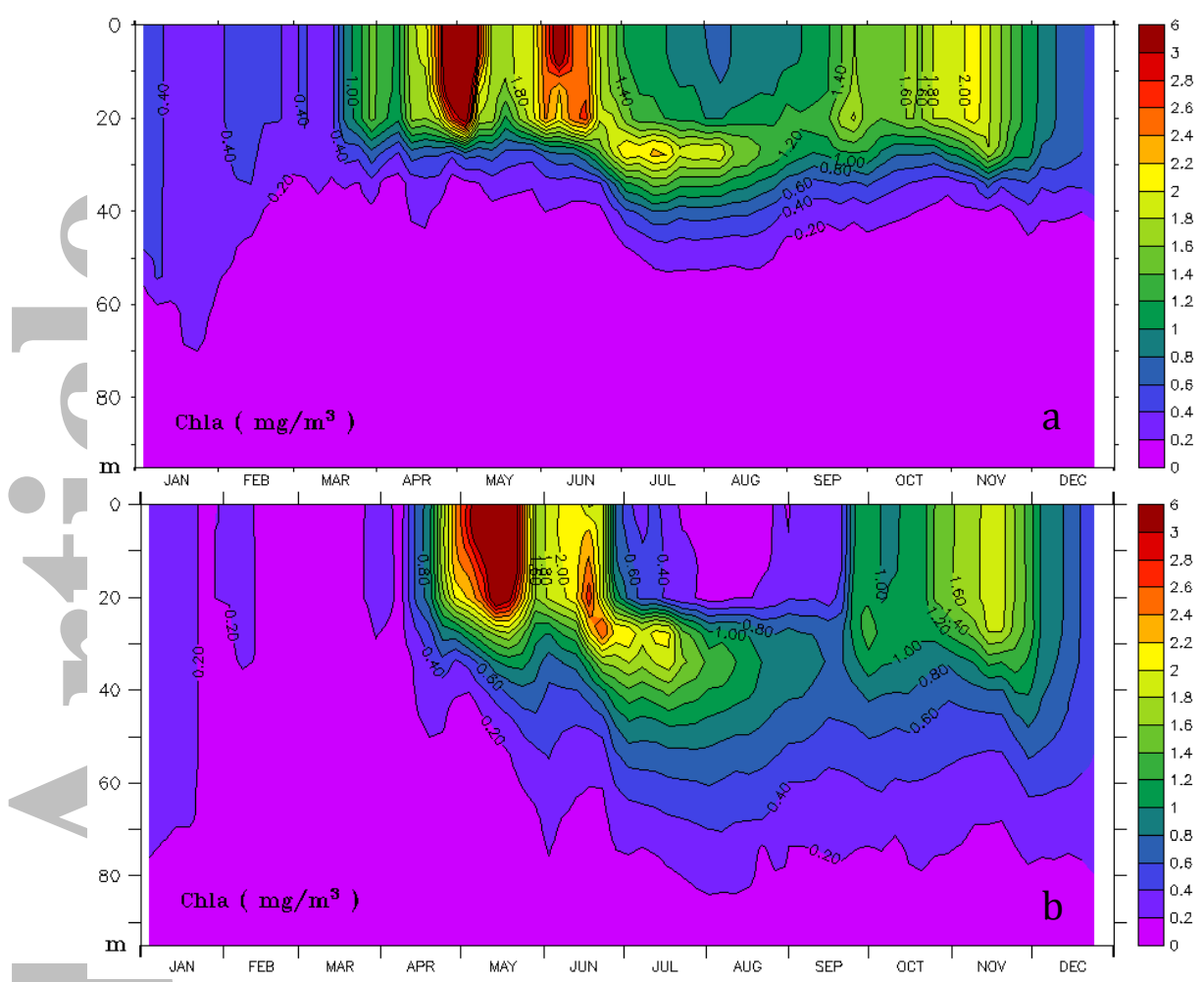

Figure 8. Experiments with/without plankton sinking. (a) No sinking case; (b) sinking case.

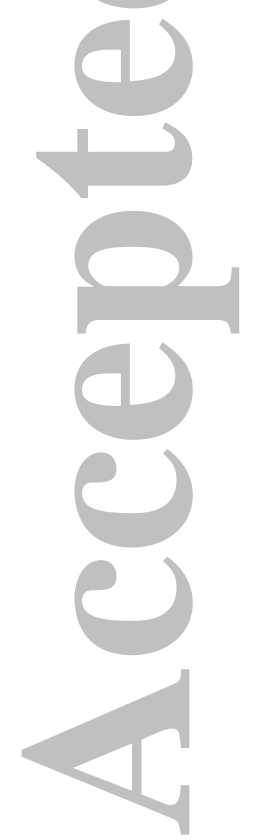




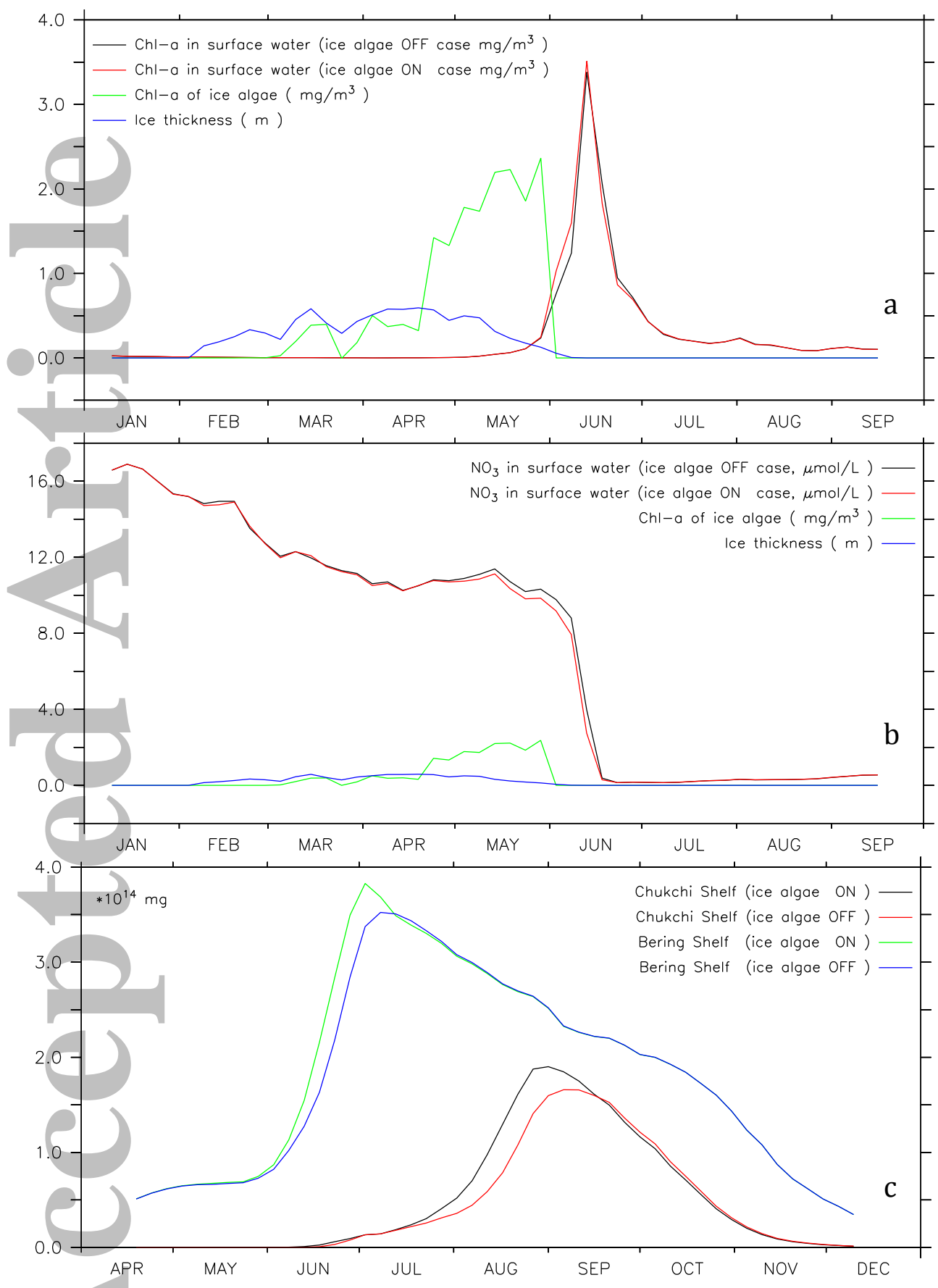

Figure 9. Experiments with/without sea ice algae in 2010 ((a) and (b) at $175^{\circ} \mathrm{W}, 61^{\circ} \mathrm{N}$, depth $100 \mathrm{~m}$ ). (a) Sea ice algae, sea ice thickness, and phytoplankton (Chl-a) in the surface water (b) Sea ice algae, sea ice thickness, and nitrate in the surface water. (c) Integrated (water mass $\times$ Chl a concentration) Chlorophyll a in the Bering Shelf and the Chukchi Shelf. 


\begin{tabular}{|c|c|c|c|c|}
\hline \multicolumn{2}{|r|}{ Description } & \multirow{2}{*}{$\begin{array}{c}\text { Value } \\
0.080\end{array}$} & \multirow{2}{*}{$\begin{array}{r}\text { Unit } \\
\mathrm{h}^{-1}\end{array}$} & \multirow{2}{*}{$\begin{array}{l}\text { Reference } \\
\text { This study }\end{array}$} \\
\hline$g_{P}$ & Maximum phytoplankton growth rate & & & \\
\hline$\mu_{\mathrm{p}}$ & Exponent coefficient related to temperature & 0.0633 & ${ }^{\circ} \mathrm{C}^{-1}$ & Eppley, 1972 \\
\hline$m_{\mathrm{p}}$ & Maximum phytoplankton respiration rate & 0.001 & $\mathrm{~h}^{-1}$ & This study \\
\hline$d_{\mathrm{p}}$ & Phytoplankton mortality rate & 0.003 & $\mathrm{~h}^{-1}$ & This study \\
\hline$\gamma_{1}$ & Light inhibition coefficient & 0.0536 & $\mathrm{~m}^{2} / \mathrm{W}$ & Platt, 1980 \\
\hline 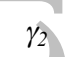 & Light acclimation coefficient & $1.795 \mathrm{E}-3$ & $3 \mathrm{~m}^{2} / \mathrm{W}$ & Platt, 1980 \\
\hline & Phytoplankton attenuation rate & 1.5 & $\mathrm{~m}^{3} / \mathrm{mg}$ & Ivlev, 1945 \\
\hline$g_{z}$ & Maximum zooplankton growth rate & 0.025 & $h^{-1}$ & Ivlev, 1945 \\
\hline & Exponent coefficient related to temperature & 0.06 & ${ }^{\circ} \mathrm{C}^{-1}$ & Ivlev, 1945 \\
\hline$m_{\mathrm{z}}$ & Maximum zooplankton excretion & 0.005 & $\mathrm{~h}^{-1}$ & This study \\
\hline$d_{\mathrm{z}}$ & Zooplankton mortality rate & 0.005 & $h^{-1}$ & This study \\
\hline$\beta$ & Zooplankton assimilation efficiency & 0.80 & & This study \\
\hline$k_{\mathrm{Si}}$ & Half-saturation constant for silicate & 4.0 & $\mathrm{mmol} / \mathrm{m}^{3}$ & This study \\
\hline & Half-saturation constant for nitrogen & 3.0 & $\mathrm{mmol} / \mathrm{m}^{3}$ & This study \\
\hline$k_{\mathrm{p}}$ & Half-saturation constant for phosphate & 0.2 & $\mathrm{mmol} / \mathrm{m}^{3}$ & This study \\
\hline$\varepsilon$ & Detritus re-mineralization rate & 0.010 & $h^{-1}$ & This study \\
\hline$W_{\mathrm{P}}$ & Phytoplankton sinking velocity & 1.0 & $\mathrm{~m} /$ day & This study \\
\hline$W_{Z}$ & Zooplankton sinking velocity & 1.0 & $\mathrm{~m} /$ day & This study \\
\hline$W_{\mathrm{D}}$ & Detritus sinking velocity & 3.0 & $\mathrm{~m} /$ day & This study \\
\hline$\eta$ & Phytoplankton self-limiting factor & 5.E-4 & & This Study \\
\hline
\end{tabular}




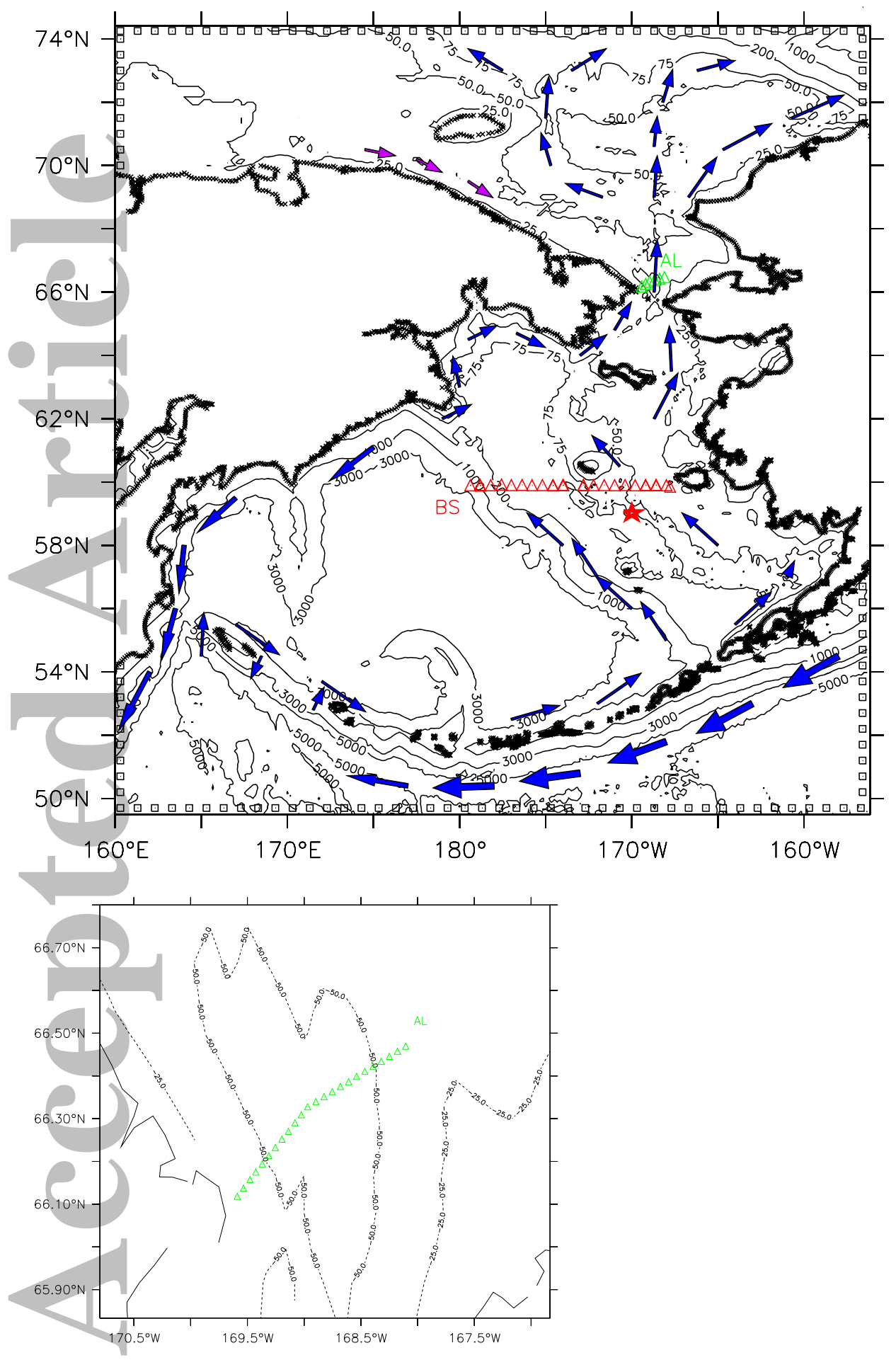

This article is protected by copyright. All rights reserved. 

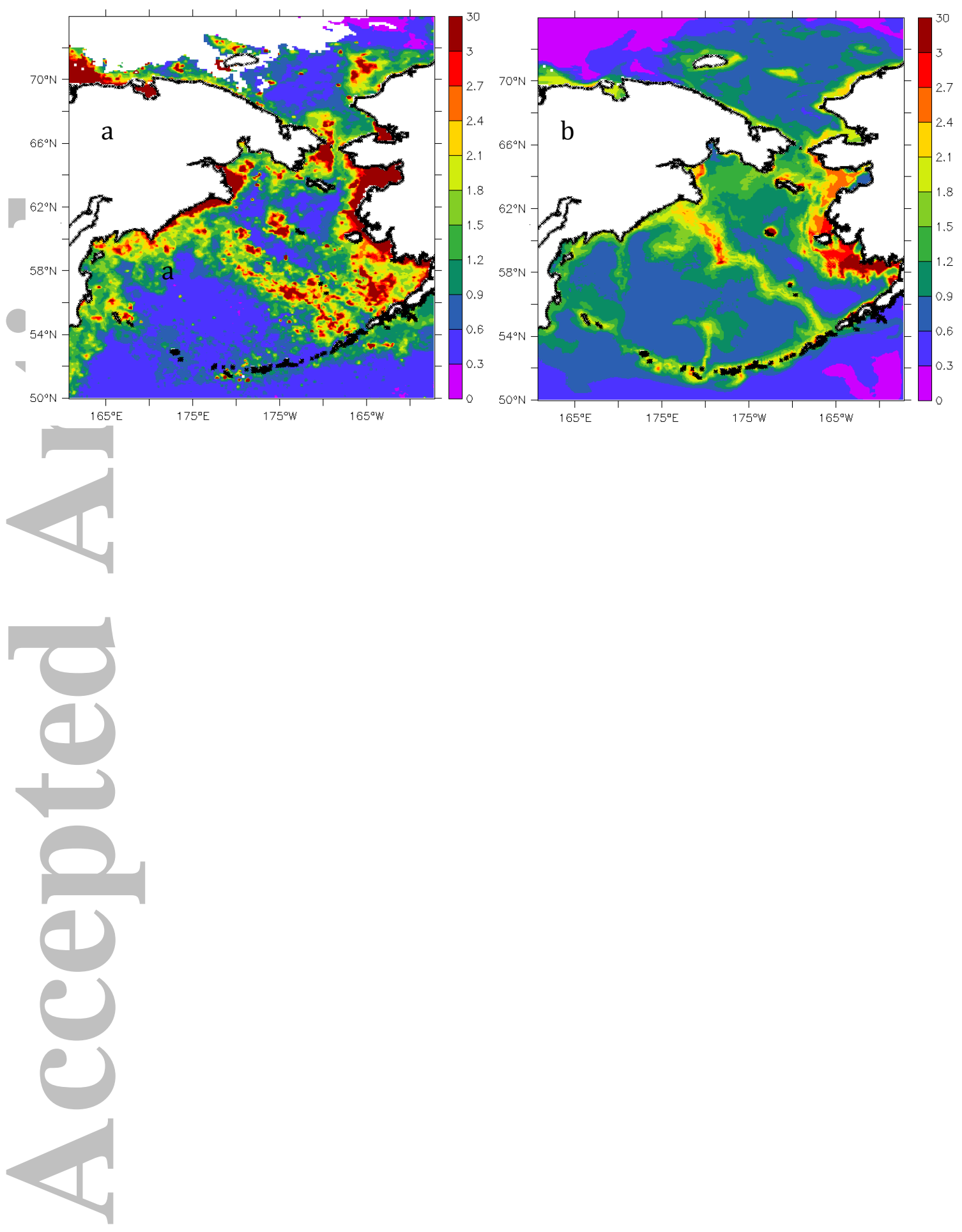

This article is protected by copyright. All rights reserved. 

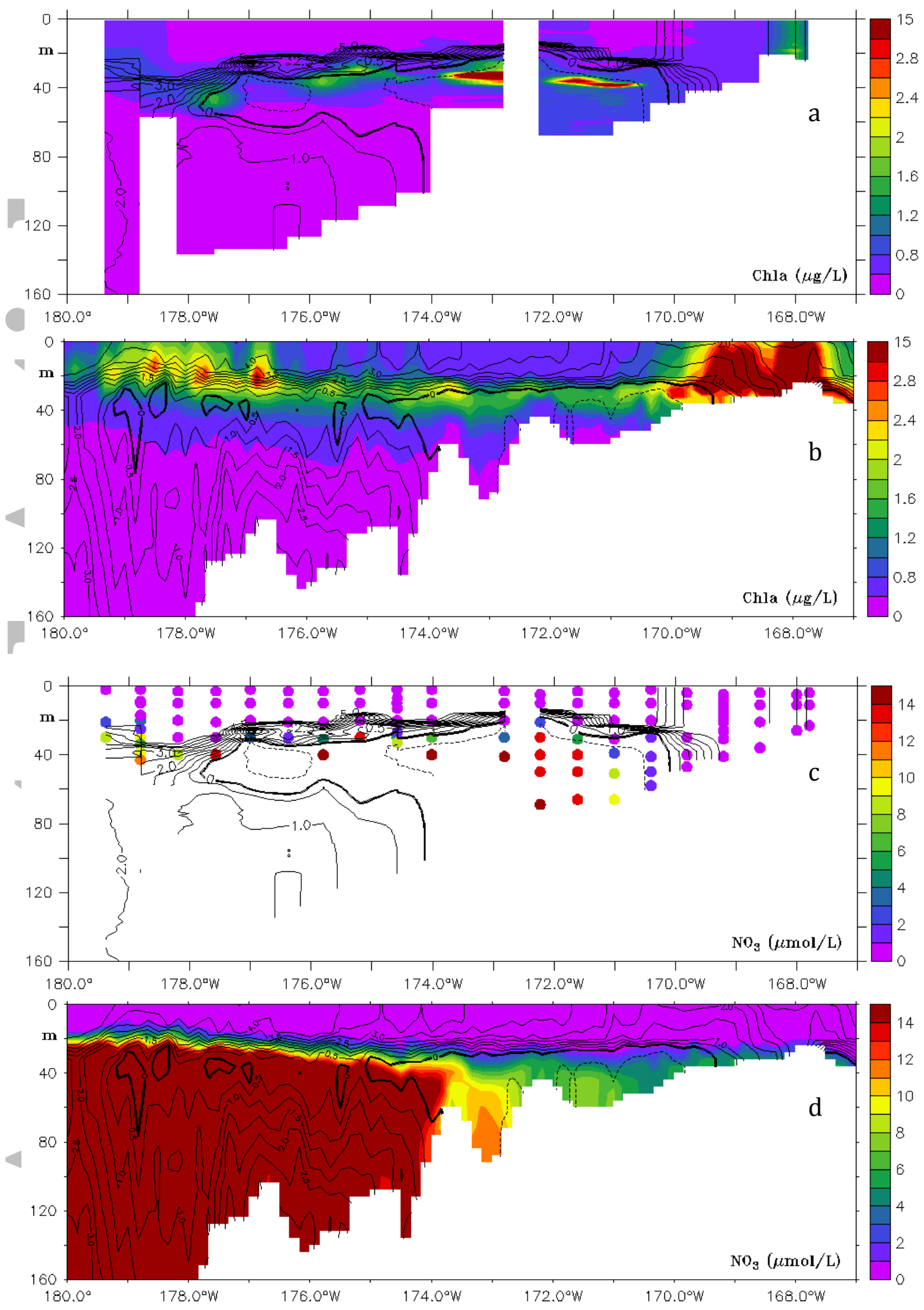

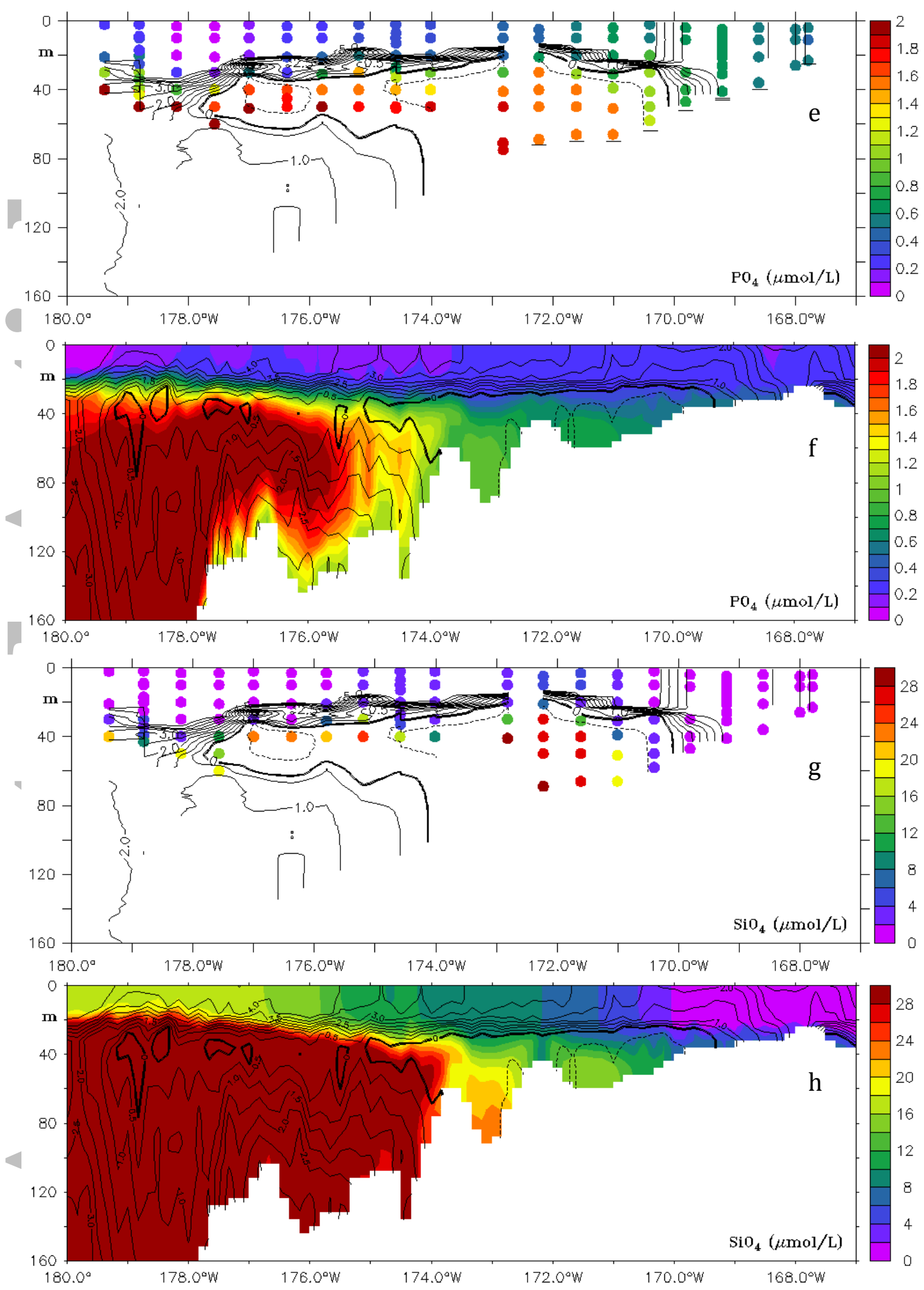

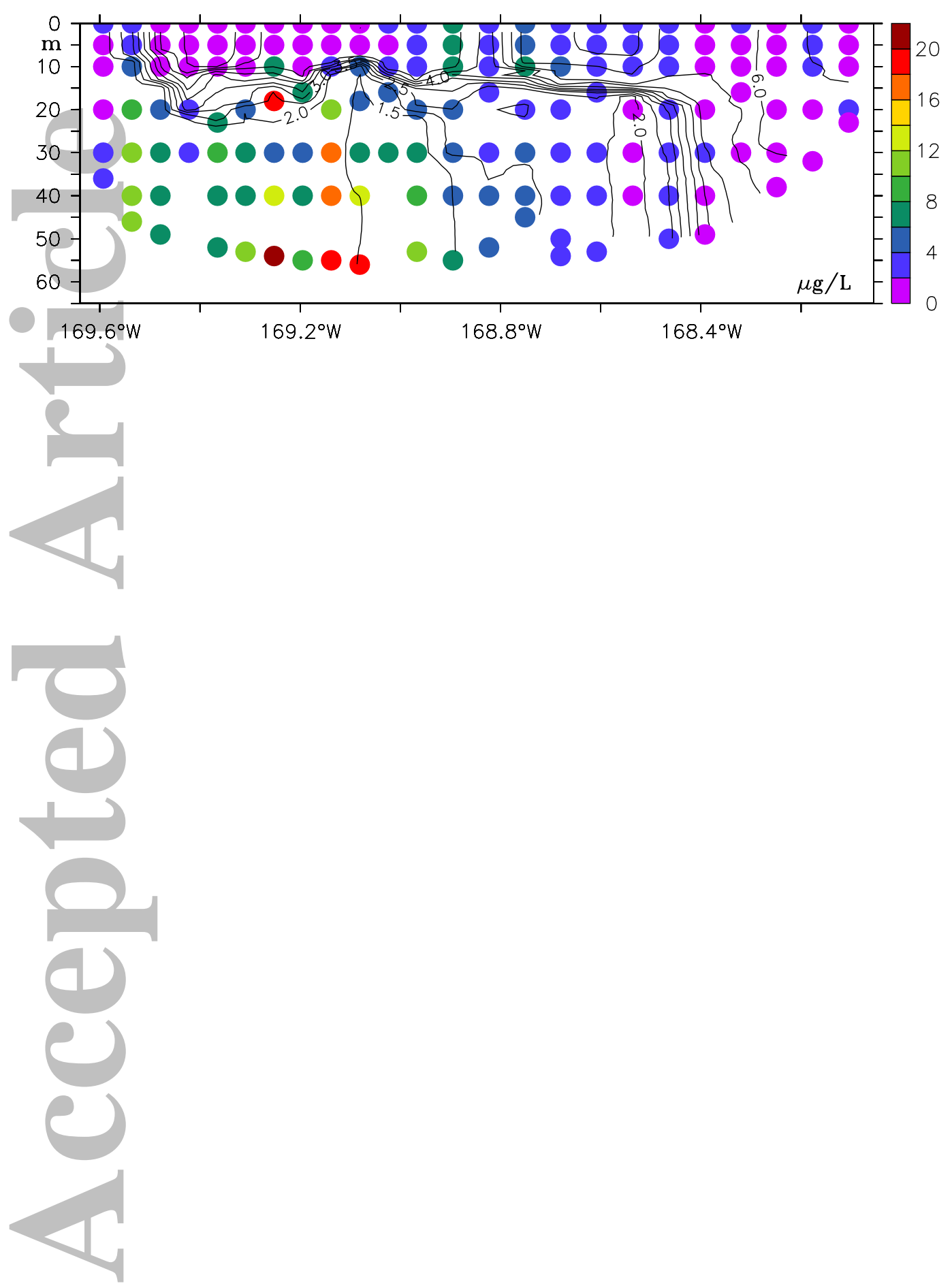


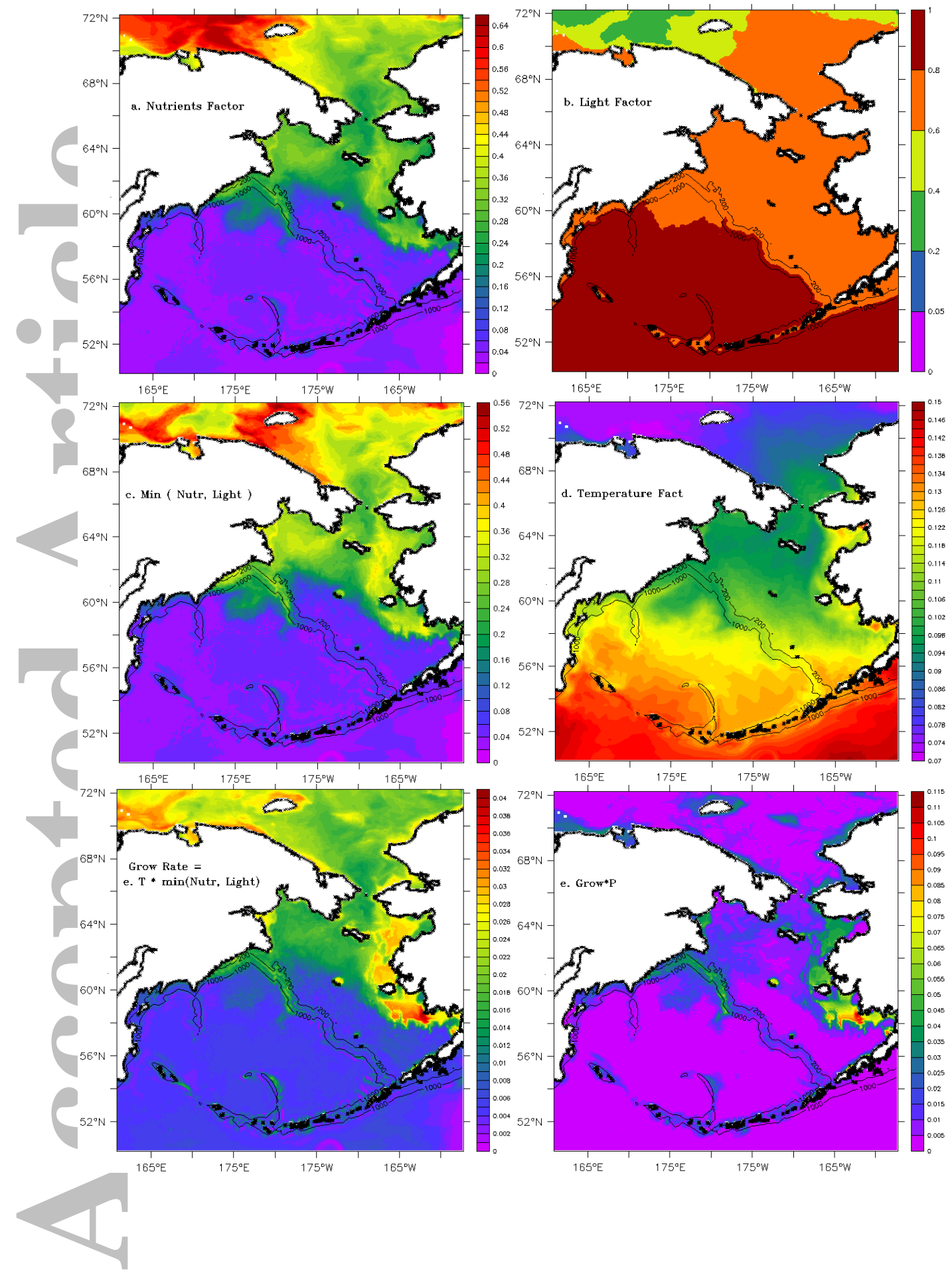

This article is protected by copyright. All rights reserved. 


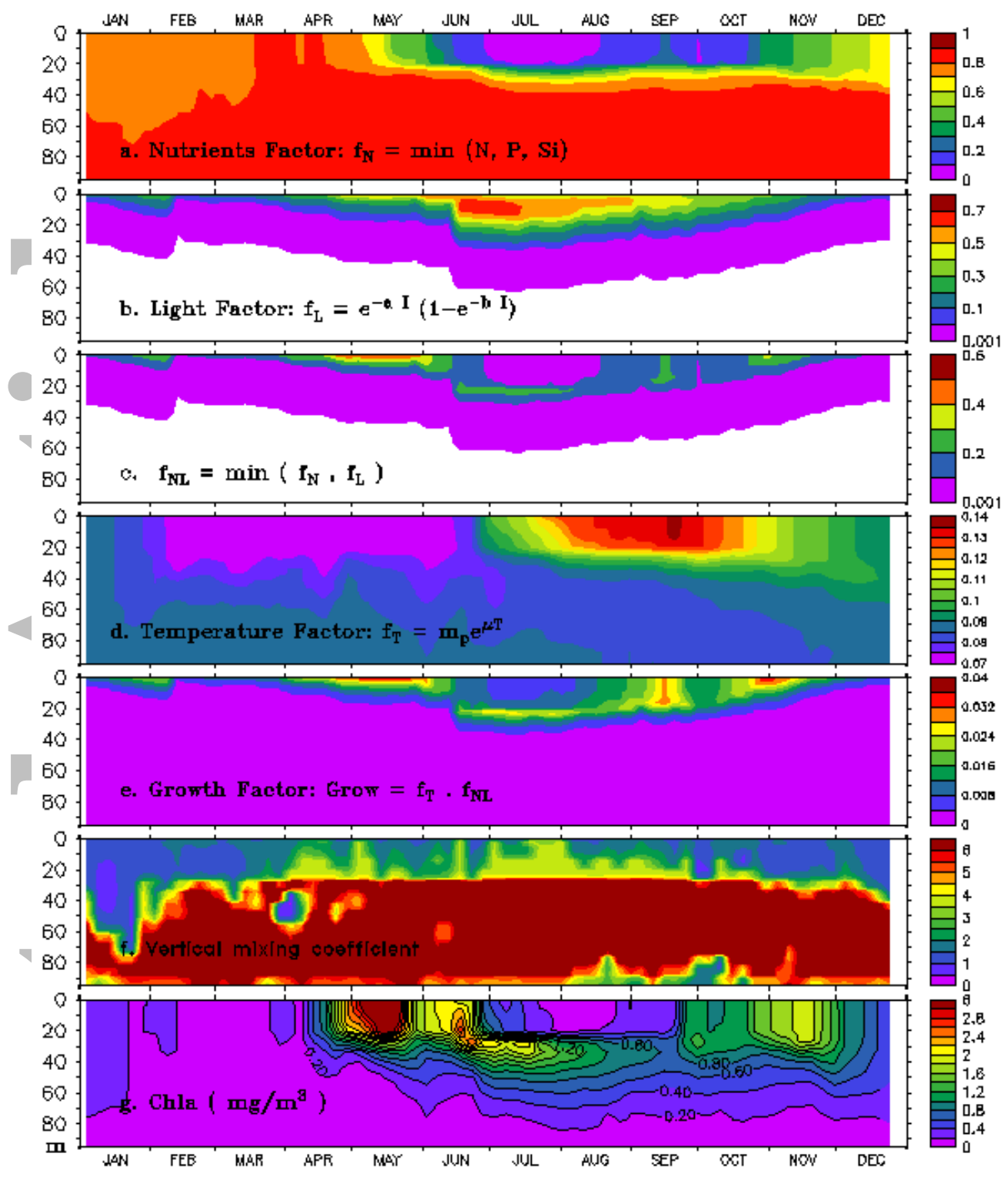

This article is protected by copyright. All rights reserved. 

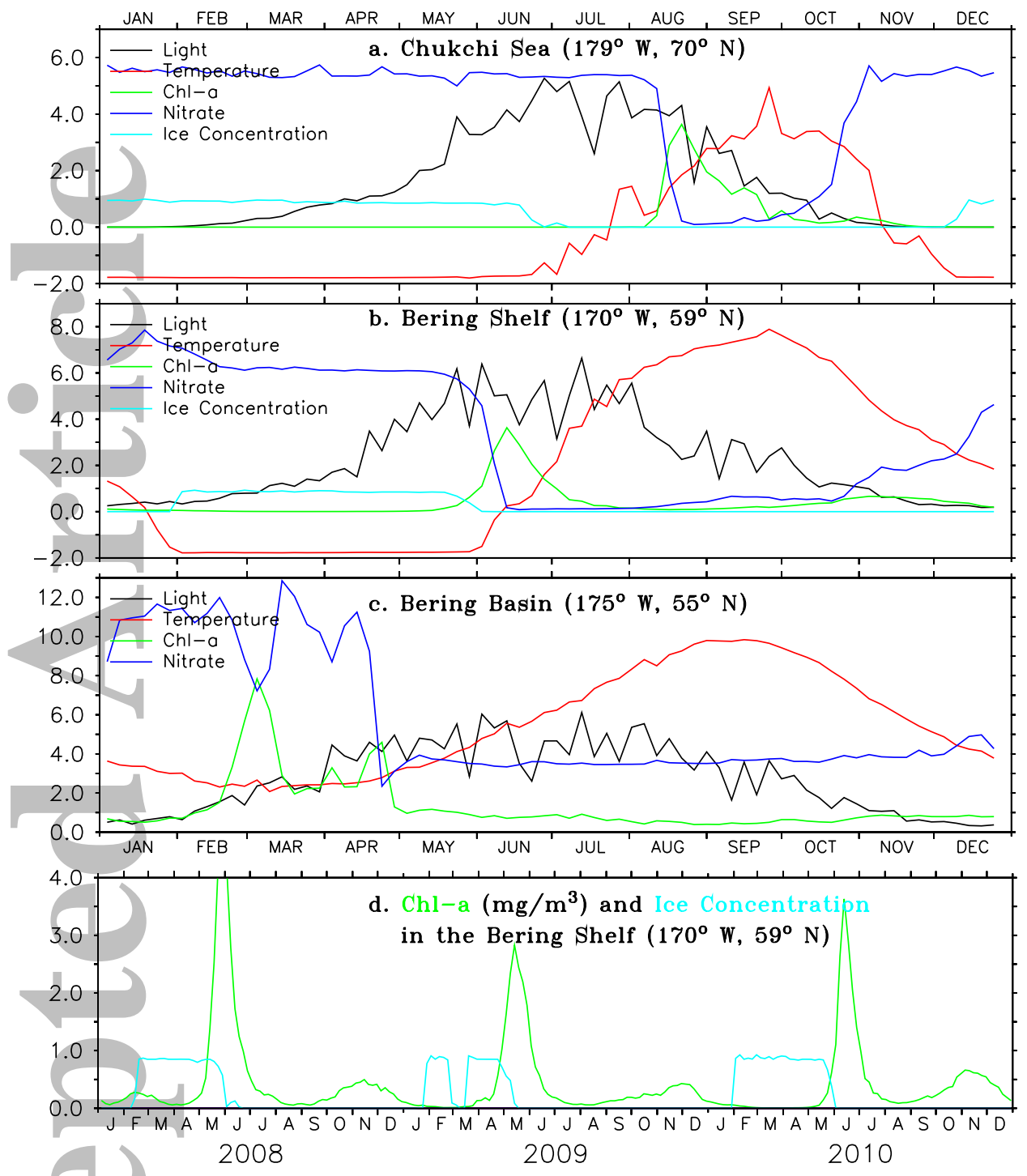

This article is protected by copyright. All rights reserved. 

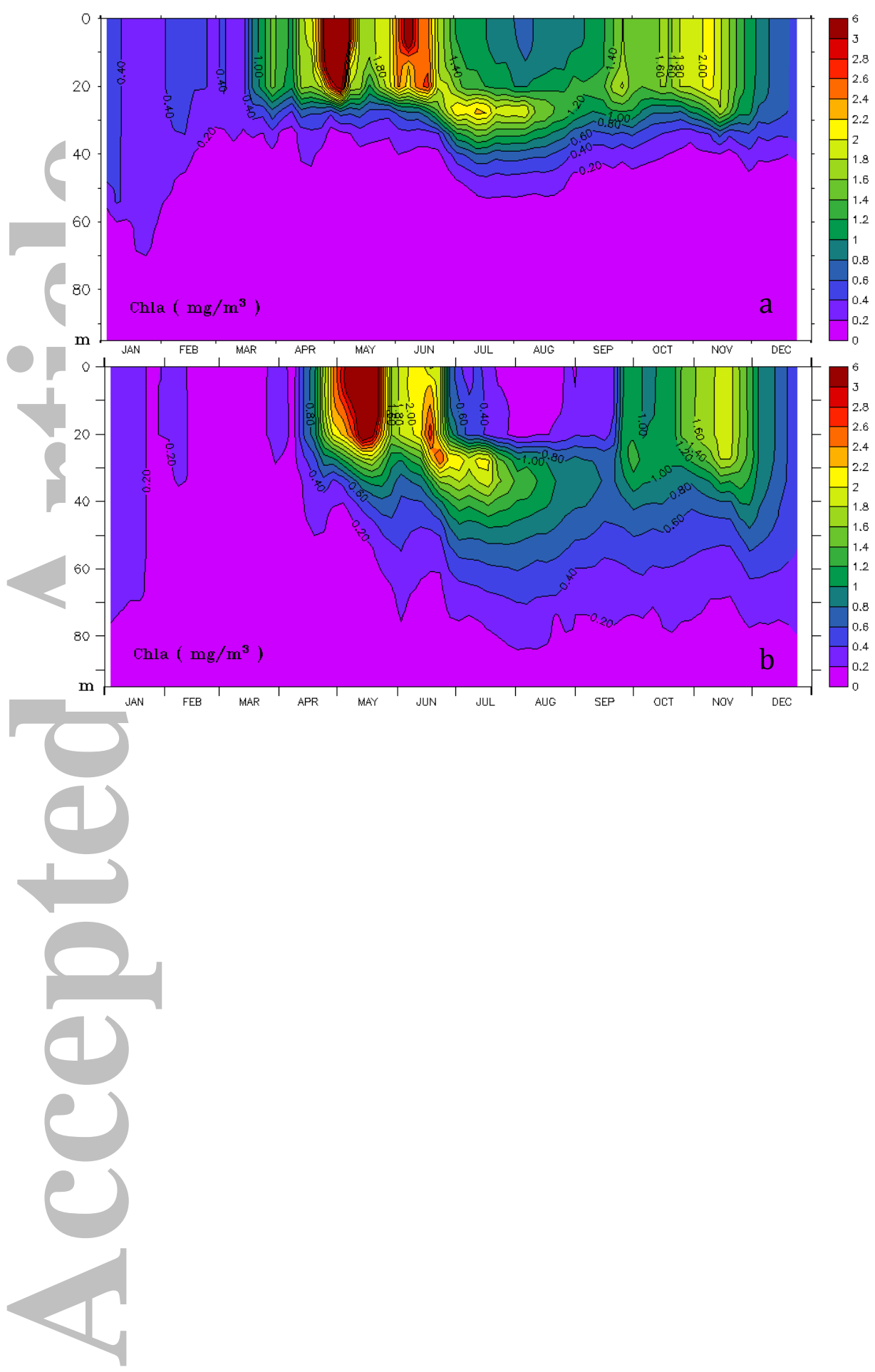


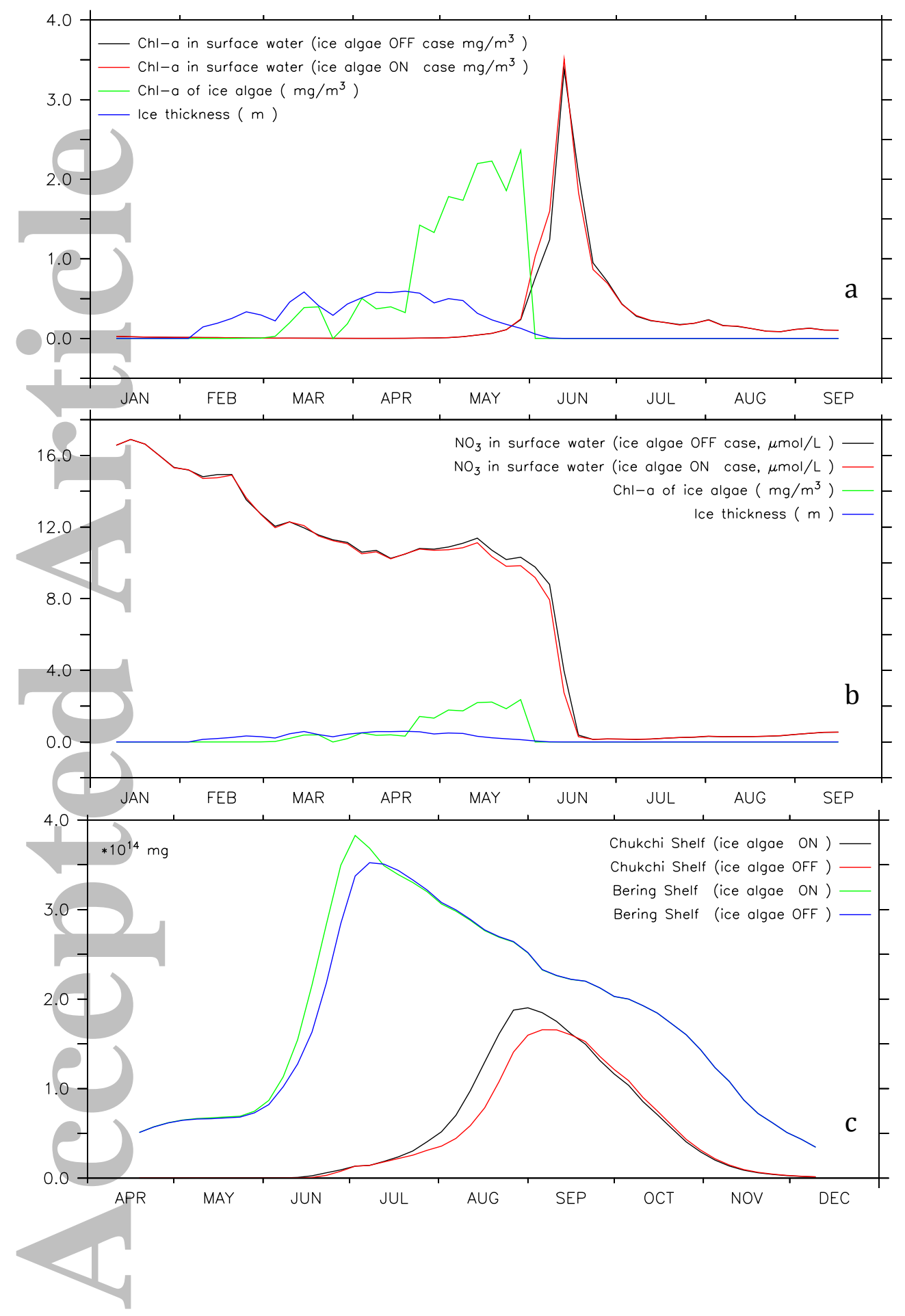

This article is protected by copyright. All rights reserved. 